\title{
THE
}

2004

\section{A Method for Obtaining the Mean Transports of Ocean Currents by Combining Isopycnal Float Data with Historical Hydrography}

\author{
Paula Pérez-Brunius \\ Tom Rossby \\ University of Rhode Island
}

Follow this and additional works at: https://digitalcommons.uri.edu/gsofacpubs

\begin{abstract}
Citation/Publisher Attribution
Pérez-Brunius, P., Rossby, T., \& Watts, D. R. (2004). A Method for Obtaining the Mean Transports of Ocean Currents by Combining Isopycnal Float Data with Historical Hydrography. J. Atmos. Oceanic Technol., 21, 298-316. doi: 10.1175/1520-0426(2004)021<0298:AMFOTM>2.0.C0;2 Available at: https://doi.org/10.1175/1520-0426(2004)021<0298:AMFOTM>2.0.C0;2
\end{abstract}

This Article is brought to you for free and open access by the Graduate School of Oceanography at DigitalCommons@URI. It has been accepted for inclusion in Graduate School of Oceanography Faculty Publications by an authorized administrator of DigitalCommons@URI. For more information, please contact digitalcommons-group@uri.edu. 


\title{
A Method for Obtaining the Mean Transports of Ocean Currents by Combining Isopycnal Float Data with Historical Hydrography
}

\author{
Paula PÉREZ-Brunius \\ Woods Hole Oceanographic Institution, Woods Hole, Massachusetts \\ TOM Rossby and D. RANDOLPH WATTS \\ Graduate School of Oceanography, University of Rhode Island, Narragansett, Rhode Island
}

(Manuscript received 2 February 2003, in final form 31 August 2003)

\begin{abstract}
This article presents a method for obtaining the mean structure of the temperature, specific volume anomaly, and velocity of an ocean current, using isopycnal float data combined with gravest empirical mode (GEM) fields calculated from historical hydrography. A GEM field is a projection on a geostrophic streamfunction space of hydrographic data, which captures most of the vertical structure associated with frontal regions. This study focuses on the North Atlantic Current-subpolar front (NAC-SPF) current system, but the float-GEM method has broad applicability to baroclinic ocean currents in general. The NAC-SPF current system is of climatic interest, being an important conduit of warm salty waters into the northern North Atlantic. It constitutes the upper limb of the thermohaline circulation of the Atlantic Ocean and plays a crucial role in the moderation of European climate, but uncertainties regarding its transport and corresponding heat fluxes remain, mainly because the structure of the system is not well known. This paper shows how isopycnal floats can be used to obtain such estimates. The performance of the float-GEM method is tested in two ways. First, two synoptic hydrographic sections (one across the NAC and the other across the SPF) are reconstructed from simulated isopycnal float pressure measurements. The baroclinic transports of volume and temperature (relative to $1000 \mathrm{dbar}$ ) across the sections are well reproduced by the method: the float-GEM transport estimates have an accuracy of $\pm 20 \%$ and a precision of $\pm 15 \%$ or less, which result in deviations of less than $\pm 10 \%$ from the "real" values. In the second test, horizontal maps of pressure and temperature on the $\delta=-12.7 \times 10^{-8} \mathrm{~m}^{3} \mathrm{~kg}^{-1}$ specific volume anomaly surface $\left(\sigma_{\theta} \approx 27.5 \mathrm{~kg} \mathrm{~m}^{-3}\right)$ are produced, using RAFOS float data from two experiments that sampled the region from 1993 to 2000. These maps compare well with similar maps constructed in previous studies and establish the consistency of the method. The good performance of the float-GEM method gives confidence in this novel way of using isopycnal floats to obtain information on the structure of the ocean. Combined with the velocity measured by the floats, it has the potential to estimate absolute transports and heat fluxes along the NAC-SPF system.
\end{abstract}

\section{Introduction}

Calculating the mean absolute mass transports and corresponding heat fluxes of the major ocean currents is one of the important tasks of oceanographers. Since simultaneous direct measurements of the velocity and hydrographic fields have been hard to obtain (particularly for extended geographical regions), such estimates are rather scarce. During the 1990s, the World Ocean Climate Experiment (WOCE) float program was undertaken to obtain the first direct current measurements of the general circulation. Today, a large amount of float data with good spatial coverage is available for various oceans, and estimates of the mean circulation from the

Corresponding author address: Paula Pérez-Brunius, Physical Oceanography Dept., Woods Hole Oceanographic Institution, MS 21, Woods Hole, MA 02543-1541.

E-mail: pperez@whoi.edu
WOCE dataset are starting to appear in the literature (e.g., Boebel et al. 1999, 2000; Ollitrault 1999; Lavender et al. 2000; Bower et al. 2002).

This study presents a method for obtaining the mean three-dimensional structure of the hydrographic and velocity field of an ocean current, by combining isopycnal float data with historical hydrography. Attention is given to the North Atlantic Current-subpolar front (NACSPF) current system, but the method has broad applicability to baroclinic ocean currents in general. The NAC-SPF system is very important from a climatic point of view: it forms part of the upper limb of the thermohaline circulation of the North Atlantic. Significant amounts of warm and salty water are carried by this current system into the subpolar region. The resulting heat flux plays a crucial role in moderating European climate (Krauss 1986).

Figure 1 shows the circulation of the upper subpolar 


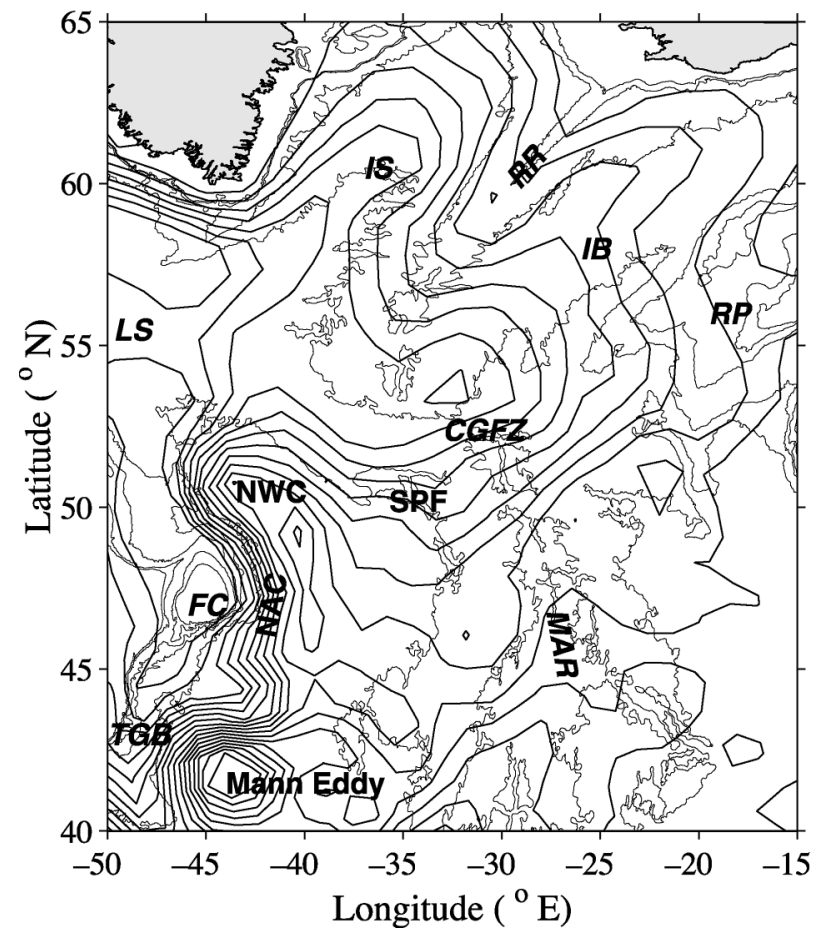

FIG. 1. Streamfunction map for the North Atlantic obtained from RAFOS floats at the $27.5 \sigma_{\theta}$ surface by Bower et al. (2002), using objective analysis to obtain the map on a grid made up of $111 \mathrm{~km}$ $\times 111 \mathrm{~km}$ squares (adapted from Bower et al. 2002, Fig. 2a). Contours are drawn every $2.5 \times 10^{3} \mathrm{~m}^{2} \mathrm{~s}^{-1}$. Dynamical features: NAC, North Atlantic Current; NWC, Northwest Corner; and SPF, subpolar front. Topographic features: MAR, Mid-Atlantic Ridge; FC, Flemish Cap; CGFZ, Charlie Gibbs Fracture Zone; RP, Rockall Plateau; TGB, tail of the Grand Banks; IB, Iceland Basin; RR, Reykjanes Ridge; IS, Irminger Sea; and LS, Labrador Sea.

North Atlantic. The NAC turns north from the Gulf Stream at the tail of the Grand Banks and continues along the continental rise until it turns east at the Northwest Corner $\left(\sim 50^{\circ} \mathrm{N}\right)$. The NAC undergoes a major transformation at this point from a sharp baroclinic front into a broader flow with embedded residual fronts. We denote this eastward flow as the SPF, which has a clear surface expression at its northernmost extent (Rossby 1999). Transport estimates exist only for a few sections across the NAC-SPF system (Worthington 1976; Clarke et al. 1980; Sy et al. 1992; Lazier 1994; Bubnov 1995; Meinen and Watts 2000), and temperature transport estimates are even scarcer (Bubnov 1995). We are not aware of attempts to obtain the downstream changes of the volume and temperature transports of the current system, which in turn would estimate the heat lost by the current on its transit through the region. Such estimates would be possible to obtain if the mean temperature, density, and velocity structure of the current system were better known. This paper shows how isopycnal floats can be used for that purpose.

Isopycnal RAFOS floats have been used to provide hydrographic information in the northern North Atlantic by Carr et al. (1997). An isopycnal RAFOS float is an acoustically tracked, neutrally buoyant drifter. Using historical hydrography, Carr et al. (1997) found a strong correlation between the potential energy anomaly (referenced to $2000 \mathrm{dbar}$ ) and the depth of the target surface of the floats. This allows them to construct a potential energy anomaly map for the NAC-SPF region, using the RAFOS float pressure records. The method presented here extends the idea put forward by Carr et al. (1997), showing how isopycnal RAFOS floats can be used to provide the full three-dimensional structure of the hydrographic field of the region sampled. The method combines the pressure data measured by the floats with gravest empirical mode (GEM) fields contructed from historical hydrography. A GEM field is a projection of hydrographic data onto geostrophic streamfunction space, capturing most of the vertical structure associated with frontal regions (Sun and Watts 2001). It takes advantage of the observational fact that the density structure is tightly locked in the vertical and varies slowly in the horizontal.

We call this technique the float-GEM method. To establish its utility for the NAC-SPF region, we undertook two tests. GEM fields of the temperature and the specific volume anomaly constructed by Pérez-Brunius (2002) and Pérez-Brunius et al. (2003b, manuscript submitted to J. Phys. Oceanogr., hereafter PRW) are used for this purpose. We first reproduce known CTD sections across the NAC-SPF, using simulated float data. Second, we apply the method to RAFOS float data from two experiments, and construct horizontal maps of temperature and depth of the $\delta=-12.7 \times 10^{-8} \mathrm{~m}^{3}$ $\mathrm{kg}^{-1}\left(\sim \sigma_{\theta}=27.5 \mathrm{~kg} \mathrm{~m}^{-3}\right)$ specific volume anomaly surface. We compare these maps with similar maps constructed directly from the pressure and temperture records from a subset of the same floats in Carr et al. (1997), to prove that the method is consistent.

The goal of the float-GEM technique is to provide a model for the vertical profiles of hydrographic properties (e.g., temperature and density) given float measurements on an isopycnal. In this sense, the method allows isopycnal floats to act as "profilers" and "current meters" at the same time. This information can then be used to estimate absolute transports, if the float dataset has good spatial and temporal coverage for the region of interest. This article focuses only on the performance of the method in reproducing the three-dimensional hydrographic field for the time period of the float experiment. A future article (Pérez-Brunius et al. 2003a, manuscript submitted to J. Phys. Oceanogr.) applies this method to estimating the absolute transports of the mass and temperature of the NAC-SPF system, by making use of the float-GEM-generated profiles and the velocity measured by the floats.

Note that when we refer to the floats being isopycnal, we means that the floats track very closely the neutral surfaces upon which water parcels move (Carr et al. 1997). We will use specific volume anomaly $(\delta)$ in this 
TABLE 1. List of specific volume anomaly surfaces and their potential density analog. Specific volume anomaly values in the first column are referenced to an intermediate temperature $\left(4.9^{\circ} \mathrm{C}\right)$ and salinity (34.6 psu). The second column has specific volume anomaly calculated using the standard $0^{\circ} \mathrm{C}$ and 35 psu values.

\begin{tabular}{|c|c|c|}
\hline $\begin{array}{l}\text { Specific volume } \\
\text { anomaly } \\
(34.6 \mathrm{psu}, \\
\left.4.9^{\circ} \mathrm{C}\right) \\
\left(10^{-8} \mathrm{~m}^{3} \mathrm{~kg}^{-1}\right)\end{array}$ & $\begin{array}{c}\text { Specific volume } \\
\text { anomaly } \\
\left(35 \mathrm{psu}, 0^{\circ} \mathrm{C}\right) \\
\left(10^{-8} \mathrm{~m}^{3} \mathrm{~kg}^{-1}\right)\end{array}$ & $\begin{array}{l}\text { Potential density } \\
\left(\sigma_{\theta} \pm 0.02\right) \\
\left(\mathrm{kg} \mathrm{m}^{-3}\right)\end{array}$ \\
\hline 70 & $\approx 142$ & $26.68 \approx 26.7$ \\
\hline 60 & $\approx 134$ & $26.78 \approx 26.8$ \\
\hline 50 & $\approx 127$ & $26.89 \approx 26.9$ \\
\hline 40 & $\approx 119$ & $26.98 \approx 27.0$ \\
\hline 30 & $\approx 109$ & $27.08 \approx 27.1$ \\
\hline 20 & $\approx 93$ & $27.18 \approx 27.2$ \\
\hline 10 & $\approx 85$ & $27.28 \approx 27.3$ \\
\hline 0 & $\approx 71$ & $27.38 \approx 27.4$ \\
\hline-10 & $\approx 64$ & $27.48 \approx 27.5$ \\
\hline-20 & $\approx 57$ & $27.59 \approx 27.6$ \\
\hline-30 & $\approx 43$ & $27.69 \approx 27.7$ \\
\hline
\end{tabular}

study, since $\delta$ surfaces are better approximations to neutral surfaces than is the more commonly used potential density $\left(\sigma_{\theta}\right)$, especially when extreme frontal properties (such as those found in the NAC-SPF region) are present (McDougall 1987, 1989; Kearns and Rossby 1998). Another advantage is that an exact streamfunction exists for specific volume anomaly surfaces (McDougall 1989), while only an approximation to this streamfunction exists for potential density surfaces (Zhang and Hogg 1992). This is of interest if absolute transports are to be computed using the velocity measured on the target surface of the floats. To help the reader, Table 1 shows various $\delta$ surfaces and their corresponding $\sigma_{\theta}$ counterparts. The $\delta$ values are referenced to $34.6 \mathrm{psu}$, and $4.9^{\circ} \mathrm{C}$, which are the mean values for the region of the NAC and SPF (Kearns 1996). It is to be noted that potential density surfaces may be reasonable approximations of neutral surfaces in regions where the temperature and salinity contrasts are less than those in the NAC-SPF system, and hence they can be used instead of specific volume anomaly at the user's discretion.

\section{Float-GEM technique}

\section{a. GEM discussion}

The large-scale thermohaline field of the ocean is subject to processes of large spatial and temporal variability. In regions around large currents, this variability is mostly due to the meandering and eddy shedding of the baroclinic front associated with the current. Near the surface, we have an added source of variability due to interaction with the atmosphere, with the largest signal found on seasonal time scales. For example, the NAC position may shift laterally up to $150 \mathrm{~km}$ north of the tail of the Grant Banks (Kearns and Rossby 1998), and Belkin and Levitus (1996) suggest that the SPF has excursions of 200-300 km near the Charlie Gibbs Frac- ture Zone. The seasonal signal is confined to the upper $200 \mathrm{dbar}$, with an amplitude at the surface of about $4^{\circ} \mathrm{C}$, or $\sigma_{\theta}=1.0 \mathrm{~kg} \mathrm{~m}^{-3}$ (Pérez-Brunius 2002; PRW).

In recent years, several studies have shown how the variability of the hydrographic field in regions where baroclinic fronts are present can be accounted for in terms of a simpler underlying dynamical concept: that vertical motions are strongly coupled thoughout the water column (Carr et al. 1997; Meinen and Watts 2000; Willeford 2001; Book et al. 2002). Sun and Watts (2001) developed a technique that helps reduce the variability in the hydrographic data associated with the meandering of baroclinic structures. This technique was derived from an earlier version first proposed by Meinen and Watts (2000). It consists of projecting the hydrographic data onto geostrophic streamfunction space. The resulting field is called a gravest empirical mode (GEM) projection. The GEM technique has succesfully captured about $90 \%$ of the variance of hydrographic data collected in the Antarctic Circumpolar Current (Sun and Watts 2001), Kuroshio (Willeford 2001; Book et al. 2002), and in the northern North Atlantic (Meinen and Watts 2000; Pérez-Brunius 2002; PRW).

GEM field projections result in $\gamma_{g}(p, \Psi, t)$ fields, where $\gamma$ is the variable we are interested in (e.g., temperature, specific volume anomaly, salinity), $p$ is pressure, $\Psi$ is a geostrophic streamfunction (such as dynamic height at the surface, for example), and $t$ is time (for the well-sampled regions of the ocean, enough data are available to construct monthly means). The subscript $g$ stands for GEM. Note that from a GEM field for the specific volume anomaly $\delta_{g}(p, \Psi, t)$, other related fields can be constructed, such as the dynamic height at every pressure level $p$ (referenced to $p_{\text {ref }}$ ):

$$
\Phi_{g}(p, \Psi, t)=-\int_{p_{\mathrm{ref}}}^{p} \delta_{g}\left(p^{\prime}, \Psi, t\right) d p^{\prime} .
$$

If the geographical region of interest is large, and the thermohaline properties change significantly within it, it is advantageous to compute individual GEM fields in smaller overlapping subregions. This will reduce discrepancies between GEM values and the hydrographic data, and thus result in a more accurate model for the mean vertical structure. The reason for having the subregions overlap is that this helps promote continuity between GEM fields of adjacent subregions.

\section{b. Float-GEM description}

While the GEM fields gives a good account of the mean vertical structure of the thermohaline field in a particular region, the next step is to obtain horizontal information by constructing the geostrophic streamfunction field in geographic coordinates. This field must be obtained independently. The idea of the floatGEM technique is to use the pressure measured by isopycnal floats as the independent measurement that 

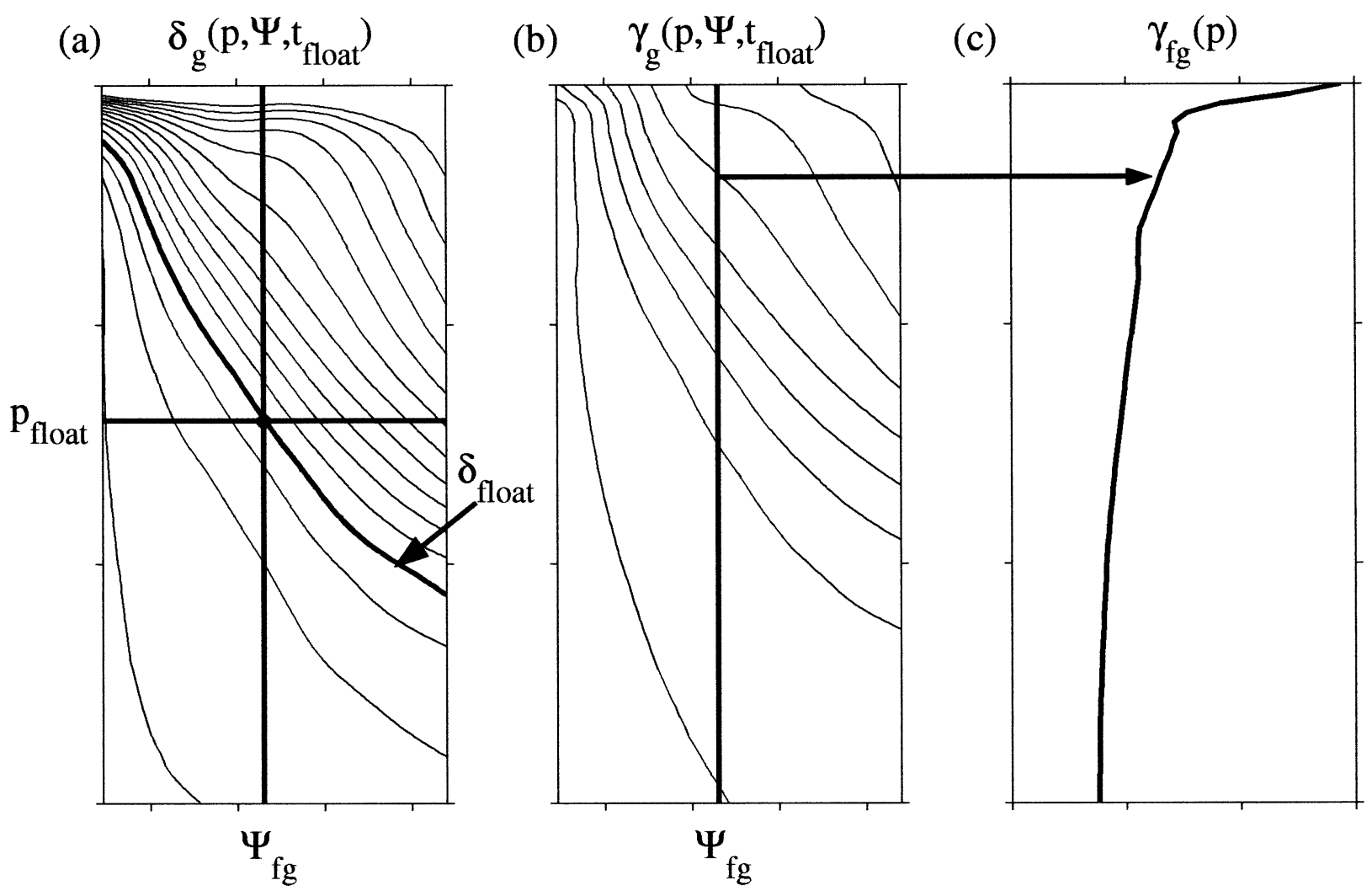

FIG. 2. Diagram illustrating the float-GEM technique, where $p$ stands for pressure, $\Psi$ is the streamfunction, and $\gamma$ is the hydrographic variable of interest. (a) The streamfunction value $\Psi_{\text {fg }}$, corresponding to the float station taken at time $t_{\text {float }}$, is found by looking up the ( $p_{\text {float }}$, $\left.\delta_{\text {float }}\right)$ pair on the specific volume anomaly GEM field $\delta_{g}\left(p, \Psi, t_{\text {float }}\right)$. (b) Once $\Psi_{\text {fg }}$ is known, the GEM field $\gamma_{g}\left(p\right.$, $\Psi$, $\left.t_{\text {float }}\right)$ is used to obtain the corresponding profile of property $\gamma_{\mathrm{fg}}(p)$, plotted in (c).

is needed to look up the geostrophic streamfunction, as will be described in the following paragraph. Once this field is known, the three-dimensional structure of all variables with corresponding GEM fields can be reproduced.

The procedure is as follows: the isopycnal float data are used in an Eulerian way. The floats are ballasted to follow a given specific volume anomaly surface $\delta_{\text {float }}$. Each float measurement of position $(X)$ and pressure $\left(p_{\text {float }}\right)$ at time $t_{\text {float }}$ is treated as a "station" measurement. At a given station $\left(X_{o}\right)$, the corresponding value of the geostrophic streamfunction $\Psi_{\mathrm{fg}}\left(X_{o}\right)$ is obtained by looking up the $\left(p_{\text {float }}, \delta_{\text {float }}\right)$ pair in the corresponding specific volume anomaly GEM field $\left[\delta_{g}\left(p, \Psi, t_{\text {float }}\right)\right]$. This is illustrated in Fig. 2. Once the value of the streamfunction is known, the vertical profile of the variable $\gamma$ is given by

$$
\gamma_{\mathrm{fg}}\left(p, X_{o}\right)=\gamma_{g}\left[p, \Psi_{\mathrm{fg}}\left(X_{o}\right), t_{\text {float }}\right],
$$

where $\gamma$ can be the specific volume anomaly, the temperature, or any other variable for which a GEM field $\gamma_{g}\left(p, \Psi, t_{\text {float }}\right)$ is available. The subscript fg stands for "float-GEM," to distinguish quantities obtained by combining the GEM fields with the float data.
Note that if the GEM fields used were constructed for several overlapping subregions, there may be float stations found in the intersection of two or more of these subregions. When this is the case, the final floatGEM-generated profile of the property variable $\gamma$, and the corresponding value of the streamfunction on that station, are given by the mean over all the subregions:

$$
\begin{aligned}
\gamma_{\mathrm{fg}}\left(p, X_{o}\right) & =\frac{1}{N} \sum_{i=1}^{N} \gamma_{\mathrm{fg}}^{(i)}\left(p, X_{o}\right) \quad \text { and } \\
\Psi_{\mathrm{fg}}\left(X_{o}\right) & =\frac{1}{N} \sum_{i=1}^{N} \Psi_{\mathrm{fg}}^{(i)}\left(X_{o}\right)
\end{aligned}
$$

where $N$ is the number of subregions containing $X_{o}$.

\section{c. Errors associated with the float-GEM technique}

There are three errors associated with the float-GEM technique: the GEM field mean-square error, the error in the pressure measurement of the float, and the error in the float ballasting.

The GEM mean-square error $\varepsilon_{g} \gamma_{g}$ describes how well the GEM field $\gamma_{g}$ reproduces the profiles of the 
hydrocasts used in its construction $\left(\gamma_{\text {hydrocasts }}\right)$ and is given by

$$
\begin{aligned}
& {\left[\varepsilon_{g} \gamma_{g}(p, \Psi, t)\right]^{2}} \\
& \quad=\left\langle\left[\gamma_{g}(p, \Psi, t)-\gamma_{\text {hydrocasts }}(p, \Psi, t)\right]^{2}\right\rangle,
\end{aligned}
$$

where $\langle\cdots\rangle$ represents the average over all the hydrocasts and $\gamma$ is the hydrographic variable of interest. This error represents the variability of the hydrographic data that is not associated with the meandering of the mean geostrophic field, such as can be produced by internal waves, the pass of temperature-salinity $(T-S)$ anomalies, and property advection by ageostrophic components of the flow. This error has been discussed in Meinen and Watts (2000), Sun and Watts (2001), and Willeford (2001). Because of the error in the pressure measured by the float $\left(\varepsilon p_{\text {float }}\right)$, the value of the geostrophic streamfunction $\left(\Psi_{\mathrm{fg}}\right)$ derived from the specific volume anomaly GEM field has an uncertainty associated with it, which we call $\varepsilon_{p} \Psi_{\mathrm{fg}}$ (see Fig. 3). The error in the geostrophic streamfunction value results in an uncertainty $\varepsilon_{p} \gamma_{\mathrm{fg}}$ on the profiles of $\gamma_{\mathrm{fg}}$. We quantify this error by taking the maximum difference between the profile corresponding to $\Psi_{\mathrm{fg}}$ and the profiles in the GEM field that correspond to the values $\Psi_{\mathrm{fg}} \pm \varepsilon_{p} \Psi_{\mathrm{fg}}$ :

$$
\begin{aligned}
& \varepsilon_{p} \gamma_{\mathrm{fg}}(p) \\
&=\max \left[\left|\gamma_{g}\left(p, \Psi_{\mathrm{fg}}, t_{\text {float }}\right)-\gamma_{g}\left(p, \Psi_{\mathrm{fg}}+\varepsilon_{p} \Psi_{\mathrm{fg}}, t_{\text {float }}\right)\right|,\right. \\
&\left.\left|\gamma_{g}\left(p, \Psi_{\mathrm{fg}}, t_{\text {float }}\right)-\gamma_{g}\left(p, \Psi_{\mathrm{fg}}-\varepsilon_{p} \Psi_{\mathrm{fg}}, t_{\text {float }}\right)\right|\right] .
\end{aligned}
$$

Similarly, an uncertainty in the float ballasting $\left(\varepsilon \delta_{\text {float }}\right)$ results in an uncertainty of $\varepsilon_{\delta} \Psi_{\mathrm{fg}}$ on the streamfunction value (see Fig. 3). This in turn translates into an error in the profile of $\gamma_{\mathrm{fg}}$, which we denote by $\varepsilon_{\delta} \gamma_{\mathrm{fg}}$. We estimate this error in the same way as $\varepsilon_{p} \gamma_{\mathrm{fg}}$ [Eq. (6)].

Hence, the total error on the float-GEM-generated profile of $\gamma$ on float station $X$ is given by

$$
\begin{aligned}
{\left[\varepsilon_{\mathrm{fg}} \gamma_{\mathrm{fg}}(p, X)\right]^{2}=} & {\left[\varepsilon_{g} \gamma_{\mathrm{fg}}(p, X)\right]^{2}+\left[\varepsilon_{p} \gamma_{\mathrm{fg}}(p, X)\right]^{2} } \\
& +\left[\varepsilon_{\delta} \gamma_{\mathrm{fg}}(p, X)\right]^{2},
\end{aligned}
$$

assuming that the three errors are independent.

In a case where the float station is found at the intersection of two or more subregions for which GEM fields have been constructed, the float-GEM errors for the profile $\gamma(p, X)$ and its corresponding streamfunction value $\Psi_{\mathrm{fg}}(X)$ are given by

$$
\begin{gathered}
{\left[\varepsilon_{\mathrm{fg}} \gamma_{\mathrm{fg}}(p, X)\right]^{2}=\frac{1}{N^{2}} \sum_{i=1}^{N}\left[\varepsilon_{\mathrm{fg}} \gamma_{\mathrm{fg}}^{(i)}(p, X)\right]^{2},} \\
{\left[\varepsilon_{\mathrm{fg}} \Psi_{\mathrm{fg}}(X)\right]^{2}=\frac{1}{N^{2}} \sum_{i=1}^{N}\left[\varepsilon_{\mathrm{fg}} \Psi_{\mathrm{fg}}^{(i)}(X)\right]^{2},}
\end{gathered}
$$

where the sum is carried out over the $N$ subregions containing station $X$.

The float-GEM errors described in this section are the associated uncertainties of the estimated profile of $\gamma_{\mathrm{fg}}$ at a given float data point (given the uncertainties of the hydrographic data and float observations used), and should be understood as the confidence interval for the modeled profile.

\section{Data}

We apply the float-GEM technique to hydrographic and RAFOS float data collected within the latitudelongitude box bounded by $\left(40^{\circ} \mathrm{N}, 50^{\circ} \mathrm{W}\right)$ to the southwest, and $\left(60^{\circ} \mathrm{N}, 15^{\circ} \mathrm{W}\right)$ to the northeast.

\section{a. GEM fields for the subpolar North Atlantic}

Monthly GEM fields of temperature, specific volume anomaly, and dynamic height have been constructed by (Pérez-Brunius 2002; PRW) for the region of interest. These fields are available for various subregions in the North Atlantic, making use of CTD and bottle data from HydroBase (Curry 1996) collected between 1910 and 1996, and during 21 WOCE cruises taken after 1996, provided by the WOCE Hydrographic Program Office at the Scripps Institution of Oceanography (Fig. 4). The GEM fields were constructed using dynamic height at $200 \mathrm{dbar}$ (referenced to $1000 \mathrm{dbar}$ ) as the geostrophic streamfunction that parameterizes the GEM fields:

$$
\Psi=\int_{1000 \mathrm{dbar}}^{200 \mathrm{dbar}} \delta_{o}(p, S, T) d p
$$

where

$$
\delta_{o}(p, S, T)=\frac{1}{\rho(p, S, T)}-\frac{1}{\rho\left(p, 35 \mathrm{psu}, 0^{\circ} \mathrm{C}\right)},
$$

and $\rho(p, S, T)$ is the in situ density at pressure $p$, salinity $S$, and temperature $T$.

The GEM fields were constructed by fitting cubic smoothing splines to the data at each pressure level, for 3 -month-long bins centered at the month of interest. Day of the year GEM fields are also obtained by linearly interpolating over time between consecutive monthly fields.

The fields so constructed explain about $90 \%$ of the horizontal variance in the regions of strong baroclinicity and stratification, for depths between 100 and $1000 \mathrm{dbar}$ in regions 1-4 in Fig. 4. However, in the subpolar region, the baroclinicity and stratification decrease, and so does the variance of the temperature and specific volume anomaly of the hydrocasts. Still, the GEM mean-square error remains about $10 \%$ of the vertical range of the specific volume anomaly and temperature variances (Pérez-Brunius 2002; PRW). This allows confidence in using the GEM projections as models of the mean vertical structure for the region we are interested in.

Pérez-Brunius (2002) and PRW found that temperature is not a single-valued function of $\Psi$ in the NAC region (subregions 1 and 2). This is due to the fact that 

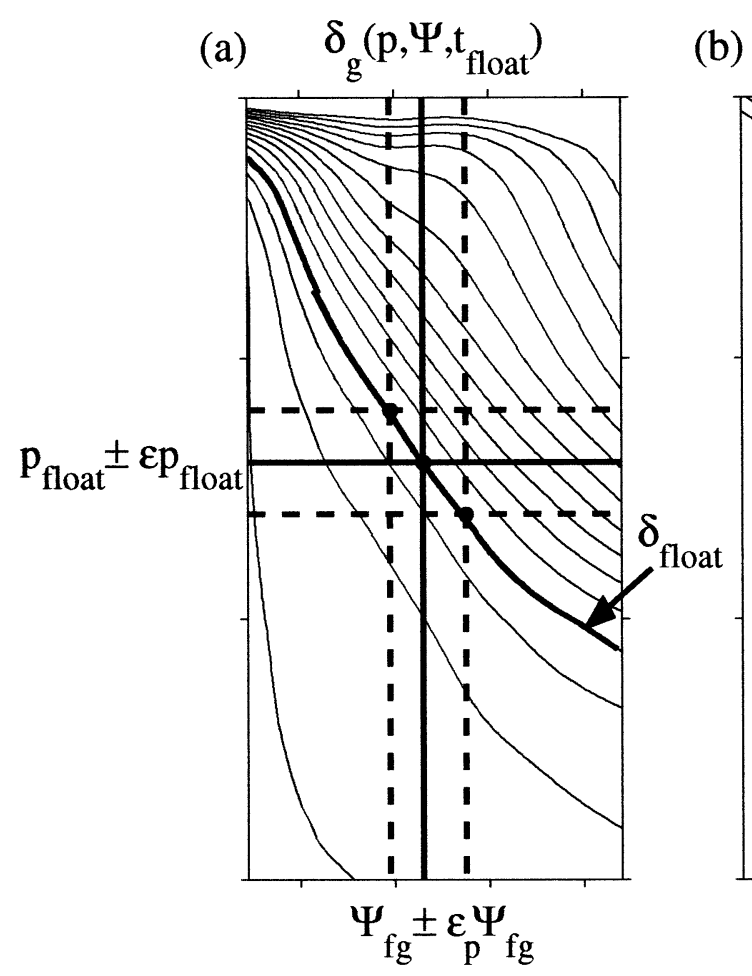

(b) $\quad \gamma_{\mathrm{g}}\left(\mathrm{p}, \Psi, \mathrm{t}_{\text {float }}\right)$

(c) $\gamma_{f g}(p) \pm \varepsilon_{p} \gamma_{f g}(p)$

(d) $\quad \delta_{\mathrm{g}}\left(\mathrm{p}, \Psi, \mathrm{t}_{\text {float }}\right)$

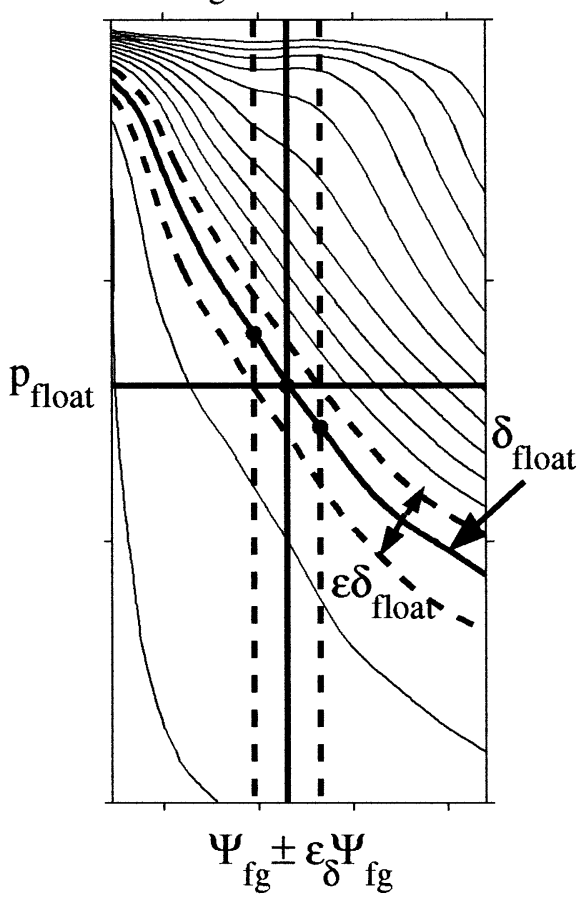

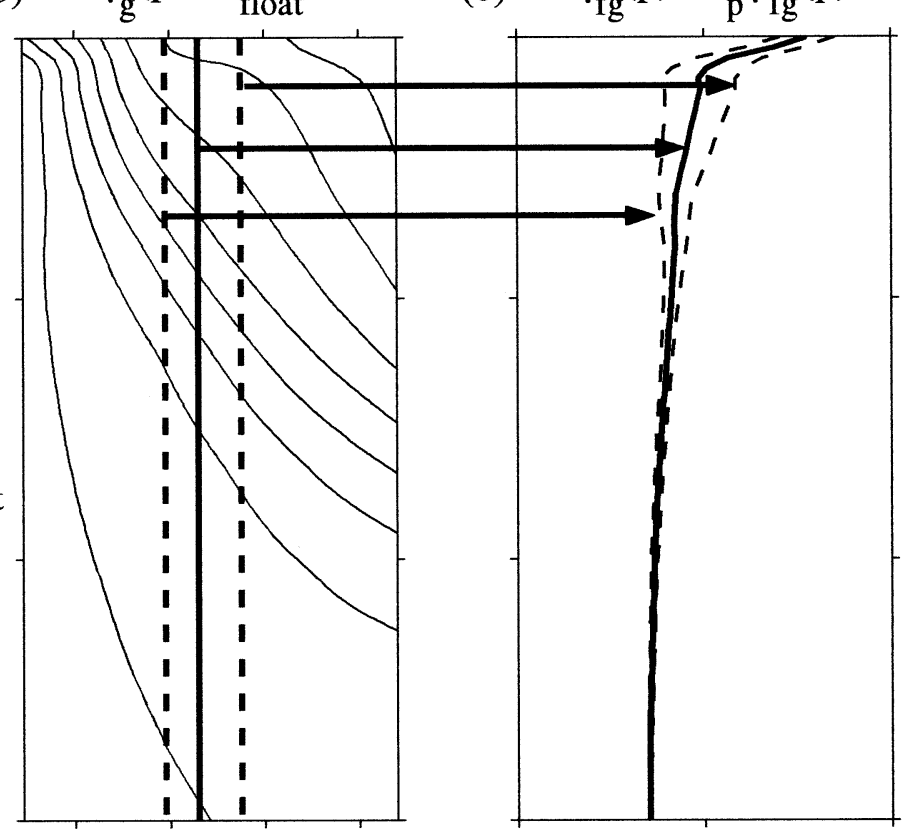

$\Psi_{\mathrm{fg}} \pm \varepsilon_{\mathrm{p}} \Psi_{\mathrm{fg}}$

(e) $\quad \gamma_{\mathrm{g}}\left(\mathrm{p}, \Psi, \mathrm{t}_{\text {float }}\right)$

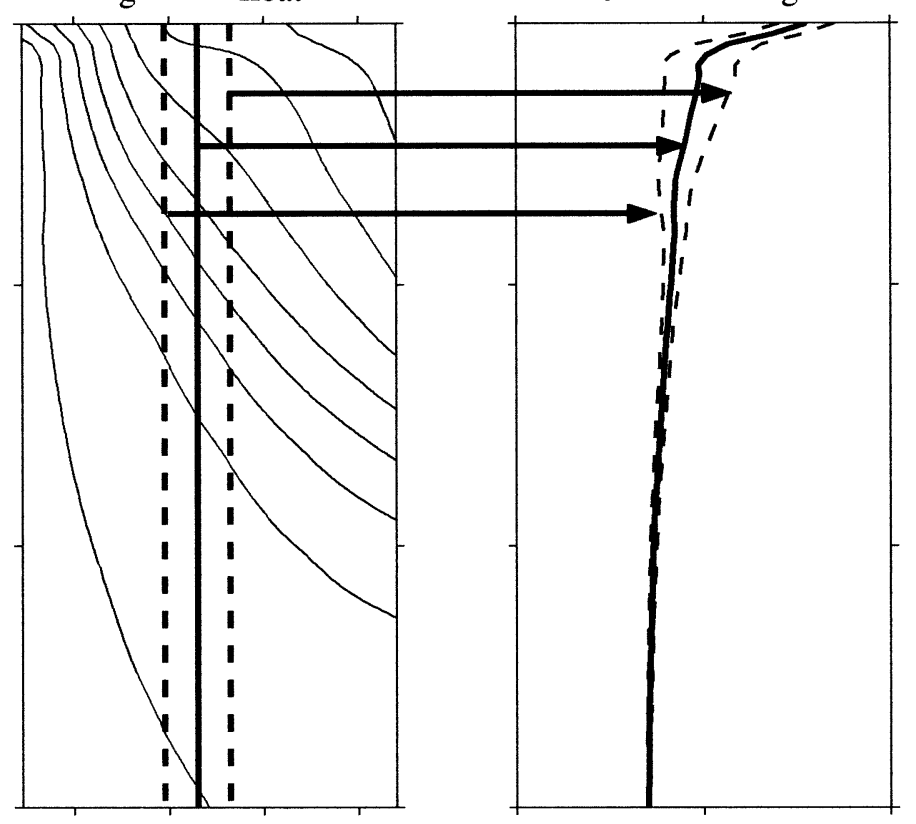

FIG. 3. Diagram illustrating the float-GEM error associated with the error of the float pressure measurement $\varepsilon p_{\text {float }}$ (upper panels) and the ballasting error of the float $\varepsilon \delta_{\text {float }}$ (lower panels). Here, $\gamma$ is the hydrographic variable of interest. (a) A set of profiles of specific volume anomaly $\delta$ correspond to the pressure interval $p_{\text {float }} \pm \varepsilon p_{\text {float }}$ on the target isopycnal of the float $\delta_{\text {float }}$. These profiles are associated with the streamfunction range $\Psi_{\mathrm{fg}} \pm \varepsilon_{p} \Psi_{\mathrm{fg}}$. (b) Similarly, a set of profiles for $\gamma$ are associated with that streamfunction interval. (c) Hence, the profile $\gamma_{\mathrm{fg}}$ has an uncertainty $\varepsilon_{p} \gamma_{\mathrm{fg}}$ defined by the profiles $\gamma_{g}\left(p, \Psi_{\mathrm{fg}}+\varepsilon_{p} \Psi_{\mathrm{fg}}\right)$ and $\gamma_{g}\left(p, \Psi_{\mathrm{fg}}-\varepsilon_{p} \Psi_{\mathrm{fg}}\right)$. An analogous discussion corresponds to figures (d)-(f). 


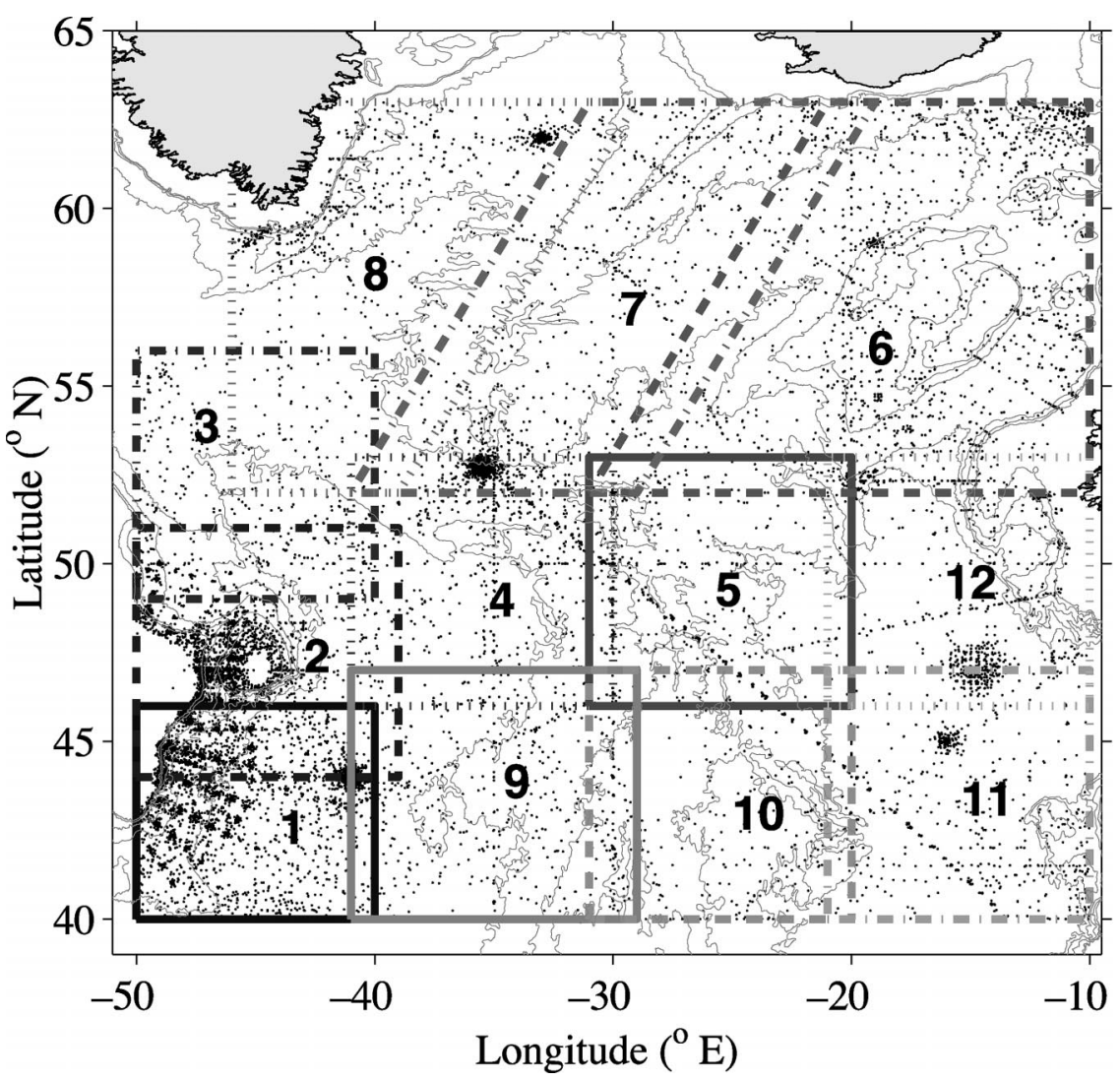

FIG. 4. Subregions selected for the construction of the GEM fields. Dots represent hydrographic stations used, obtained from HydroBase (Curry 1996) and 21 WOCE cruises that took place in the late 1990s.

the cold and fresh Labrador Current waters, which flow along the inshore side of the NAC, have the same density as the adjacent warm and salty NAC waters. Hence, there is no dynamic height front separating these two currents between 200 and 1000 dbar, and the streamfunction $\Psi$ cannot distinguish them. Figure 5 shows the bimodal dependence of temperature with streamfunction for subregion 1. Pérez-Brunius (2002) and PRW constructed the monthly temperature GEM field of subregions 1 and 2 for the warm waters of the NAC. For this, the distribution of temperature along the specific volume anomaly surface $\delta=-5 \times 10^{-8} \mathrm{~m}^{3} \mathrm{~kg}^{-1}\left(\approx \sigma_{\theta}=27.43\right.$ $\left.\mathrm{kg} \mathrm{m}^{-3}\right)$ was used to obtain the cutoff value $\left(3.1^{\circ} \mathrm{C}\right)$ that divides the two modes. Hence, only stations with temperatures higher than that cutoff value were used for the construction of the monthly temperature GEM for the warm NAC waters $\left[T_{g}(p, \Psi\right.$, month $\left.)\right]$. It is important to note that the cutoff value depends on the $\delta$ surface used to distinguish between the two modes. The rest of the stations are assumed to be sampling Labrador Current waters, which specify their own annual mean GEM field for temperature $T_{g}^{\mathrm{LC}}(p, \Psi)$ for subregions 1 and 2. There is not enough coverage for all seasons to construct monthly means. The match between the temperature
GEMs and the data at various levels for subregion 1 is shown in Fig. 5.

So far, the float-GEM method presented in section 2 does not allow one to choose which of the two values of the bimodal temperature GEM field is to be used for float stations within the NAC-Labrador Current region. This is where the temperature measured by the floats becomes handy; it provides the additional information needed to distinguish between the two GEMs. For a float station $X_{o}$, which has $\Psi_{\mathrm{fg}}\left(X_{o}\right)$ within the range at which the temperature GEM is bimodal, the corresponding profile of temperature $T_{\mathrm{fg}}\left(p, X_{o}\right)$ is given by

$T_{\mathrm{fg}}\left(p, X_{o}\right)= \begin{cases}T_{g}^{\mathrm{LC}}\left(p, \Psi_{\mathrm{fg}}\right) & \text { if } T_{\text {float }} \leq T_{\text {cutoff }} \\ T_{g}\left(p, \Psi_{\mathrm{fg}}, t_{\text {float }}\right) & \text { if } T_{\text {float }}>T_{\text {cutoff }},\end{cases}$

where $T_{\text {cutoff }}$ is the temperature that divides the two modes on the float's target surface $\delta_{\text {float }}$, and $t_{\text {float }}$ corresponds to the day of the year at which the float measurement took place. We obtain the cutoff temperature by making a histogram of temperature on $\delta_{\text {float }}$ from the hydrographic data, in the same way that the cutoff temperature was chosen for the construction of the temperature GEM in Pérez-Brunius (2002) and PRW. 


\section{b. Float data for the region}

We use data from RAFOS floats deployed during two experiments: the NAC experiment (1993-95), and the Atlantic Climate Change Experiment (ACCE), which took place between 1997 and 2000.

From the NAC experiment, we use 50 floats targeted for $\sigma_{\theta}=27.2 \mathrm{~kg} \mathrm{~m}^{-3}\left(\delta \approx 20 \times 10^{-8} \mathrm{~m}^{3} \mathrm{~kg}^{-1}\right)$ and 37 floats targeted for $\sigma_{\theta}=27.5 \mathrm{~kg} \mathrm{~m}^{-3}(\delta \approx-10 \times$ $\left.10^{-8} \mathrm{~m}^{3} \mathrm{~kg}^{-1}\right)$. They were deployed during three different cruises that took place in July-August 1993, November-December 1993, and October-November 1994. Programmed to sample for 300 days, the floats collected position, temperature, and pressure data twice a day (Anderson-Fontana et al. 1996).

From the ACCE experiment, we use the data from 50 floats ballasted for $\sigma_{\theta}=27.5 \mathrm{~kg} \mathrm{~m}^{-3}(\delta \approx-10 \times$ $\left.10^{-8} \mathrm{~m}^{3} \mathrm{~kg}^{-1}\right)$. These floats were deployed across the SPF during two cruises. The first cruise took place in November 1997, and the second one in July 1998. The floats sampled position once a day, and temperature and pressure six times a day. Their missions were programmed to be 540 days long (Anderson-Fontana et al. 2001). The accuracy of the RAFOS float pressure measurement is $10 \mathrm{dbar}$ and that of temperature is $0.1^{\circ} \mathrm{C}$ (Carr et al. 1997).

These two datasets result in over 64000 float "stations." To ensure a degree of statistical independence, we subsampled the data so that only stations that were more than $\Delta t=2.5$ days and $\Delta x=30 \mathrm{~km}$ apart from each other remained. These are the integral time and length scales, respectively, for this region (Zhang et al. 2001). This results in 14264 independent float stations, with a spatial distribution shown in Fig. 6.

\section{FLOAT BALLASTING}

Knowing with accuracy the specific volume anomaly of the float is crucial for the float-GEM technique. To estimate the actual value of $\delta_{\text {float }}$ for each float, we made use of the specific volume anomaly profile obtained by the CTD cast taken at the floats deployment site. A set of $\delta$ values was obtained by matching the CTD specific volume anomaly profile with the first 10 pressure measurements taken by the floats. This corresponds to the first 5 (2) days of data for the NAC (ACCE) experiment. The $\delta_{\text {float }}$ is then given by the mean of those values, using the standard deviation as the uncertainty in float ballasting $\varepsilon \delta_{\text {float }}$. We choose the 10 first measurements to ensure sufficient stability and precision in the average and standard deviation of the estimated $\delta$ of the float. For the $10 \%$ of the floats that had no simultaneous CTD cast, the mean and standard deviation of the $\delta_{\text {float }}$ for each float experiment were used. The results of the float ballasting are shown in Tables $2-4$.

\section{c. Float-GEM errors for the northern North Atlantic}

Figure 7 shows the annual mean float-GEM errors for specific volume anomaly in subregion 1. Errors for temperature in subregion 4 are shown in Fig. 8. The results for the other subregions are very similar. The errors were calculated using $\delta_{\text {float }}=-12.7 \times 10^{-8} \mathrm{~m}^{3}$ $\mathrm{kg}^{-1}$ as the target surface for the floats (close to the mean value for the ACCE and deep NAC floats), and $\varepsilon p_{\text {float }}=10 \mathrm{dbar}$ and $\varepsilon \delta_{\text {float }}=3 \times 10^{-8} \mathrm{~m}^{3} \mathrm{~kg}^{-1}$ as the float errors. The float ballasting error represents the mean error for the floats that had a CTD cast associated with them when deployed.

Near the surface, the largest error for both temperature and specific volume anomaly is the GEM meansquare error. In the pycnocline, the error due to uncertainty in float ballasting is the largest. Notice that the error due to the uncertainty of the float pressure is much smaller than either of the other two. The total error is generally less than $10 \%(15 \%)$ of the vertical range in specific volume anomaly (temperature). Note that the float-GEM errors for both temperature and specific volume anomaly appear to follow the sloping specific volume anomaly surfaces.

\section{Test of method: Reconstruction of hydrographic sections from simulated float data}

\section{a. Hydrographic sections}

To test how well the float-GEM technique reproduces the vertical structure of the hydrographic field at any given time, two transects of CTD profiles were reconstructed using simulated float data (Fig. 9). The first one is a transect across the NAC, near the tail of the Grand Banks, taken on board the R/V Oceanus during 1-7 August 1993. This section has been discussed by Meinen et al. (2000). The second one is a section across the SPF, along $37^{\circ} \mathrm{W}$, taken during 22-24 July 1998, on board the R/V Knorr. These two sections were not included in the construction of the GEM fields (section $3 \mathrm{a})$; hence, they provide an independent set to check the performance of the technique.

\section{b. Simulated float data}

Float measurements are simulated by obtaining the pressure and temperature of $\delta_{\text {float }}=-10 \times 10^{-8} \mathrm{~m}^{3}$ $\mathrm{kg}^{-1}\left(\sim \sigma_{\theta}=27.5 \mathrm{~kg} \mathrm{~m}^{-3}\right)$ from the CTD casts. The cruise stations are the simulated float stations. We choose $\delta_{\text {float }}$ to be within the main thermocline. It also corresponds to the target surface for the ACCE and deeper NAC floats described in section $3 \mathrm{~b}$. To obtain realistic float-GEM errors, we use the mean ballasting error of $\varepsilon \delta_{\text {float }}= \pm 3 \times 10^{-8} \mathrm{~m}^{3} \mathrm{~kg}^{-1}$, as derived from the NAC and ACCE floats for which a CTD cast was available at float deployment. The uncertainty in pressure used in the one associated with the RAFOS float pressure sensor $\varepsilon p_{\text {float }}=10 \mathrm{dbar}$ (see section $3 \mathrm{a}$ ). 

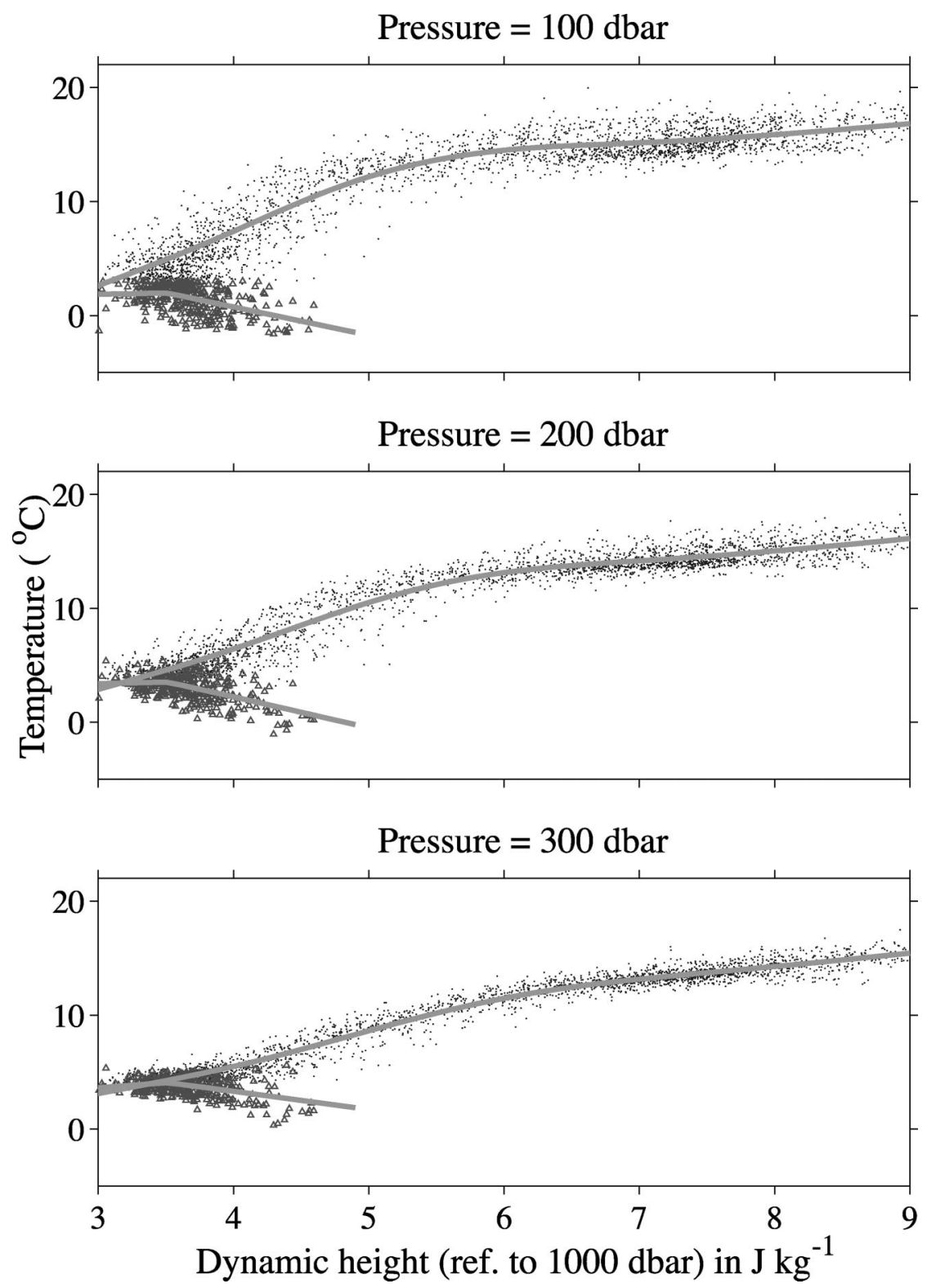

FIG. 5. Temperature vs dynamic height $\Psi$ at various pressure levels, for the region of the southern NAC (subregion 1). Note the bimodal structure of the field for $\Psi<5 \mathrm{~J} \mathrm{~kg}^{-1}$. The triangles represent hydrocasts in the Labrador Current, while the dots are stations taken within the NAC. The bold lines are the spline fits for the GEM fields. For the case of the warm NAC waters, the line corresponds to the annual mean $T_{s}$ field, while the fit for the cold waters corresponds to the temperature vs dynamic height $\Psi^{g}$ at various pressure levels, for the region of the southern NAC (subregion 1). Note the bimodal structure of the field for $\Psi<5 \mathrm{~J} \mathrm{~kg}^{-1}$. The triangles represent hydrocasts in the Labrador Current, while the dots are stations taken within the NAC. The bold lines are the spline fits for the GEM fields. For the case of the warm NAC waters, the line corresponds to the annual mean $T_{g}$ field, while the fit for the cold waters corresponds to the $T_{g}^{\mathrm{LC}}$ field.

\section{c. Simulated float-GEM profiles}

We now have the data needed to apply the float-GEM technique in an attempt to recreate the specific volume anomaly, temperature, and dynamic height transects from the GEM fields presented in section 2.
For the NAC section, the August GEM fields in subregion 1 are used. To distinguish between the two modes of the temperature GEM, we use the simulated float temperature. The corresponding cutoff value for temperature in the $\delta_{\text {float }}=-10 \times 10^{-8} \mathrm{~m}^{3} \mathrm{~kg}^{-1}$ surface was found to be $T_{\text {cutoff }}=3.5^{\circ} \mathrm{C}$. 


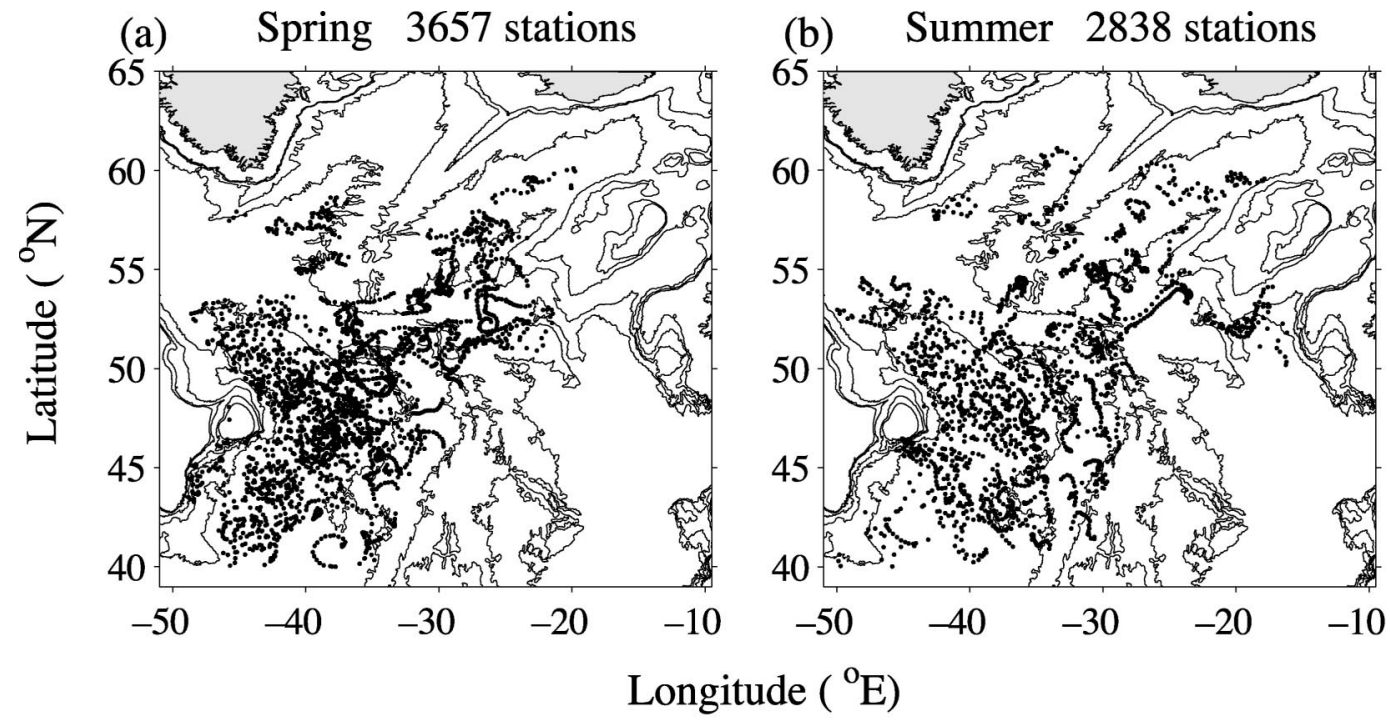

(c) Fall 3490 stations

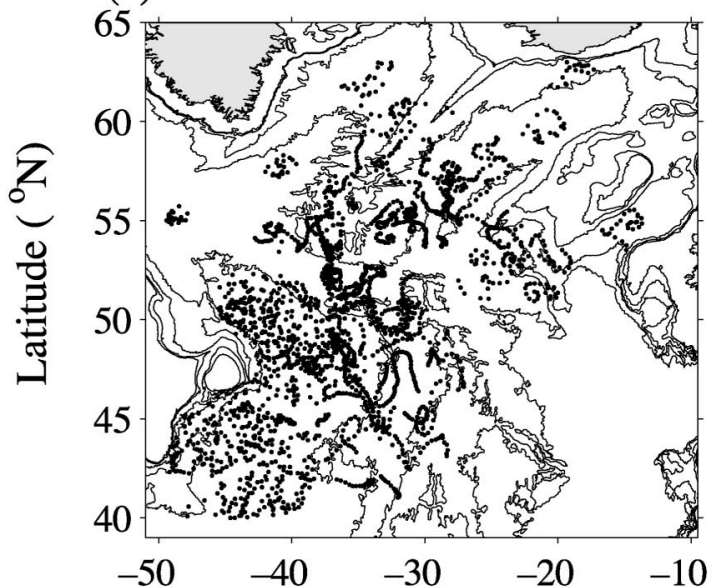

(d) Winter 4279 stations

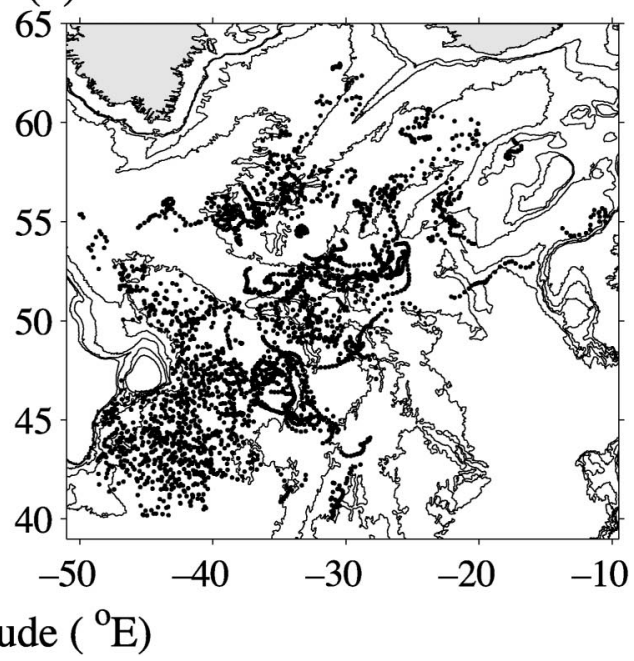

FIG. 6. Distribution of statistically independent RAFOS float stations from the NAC (1993-95) and ACCE (19972000) experiments, for (a) spring (Feb-Apr), (b) summer (May-Jul), (c) fall (Aug-Oct), and (d) winter (Nov-Jan).

In reproducing the SPF section, the July GEM fields from subregions 4 and 7 are used. In this case, the temperature GEM fields are single valued, so there is no need of the simulated float temperature data. Note that there are four stations found in the intersection of the two subregions (Fig. 9).

The profiles of specific volume anomaly, temperature, and dynamic height (referenced to $1000 \mathrm{dbar}$ ) are ob- tained for each float station, using the float-GEM method described in section 2 .

\section{d. Simulated baroclinic transports}

To check how well the float-GEM technique reproduces the distribution of the specific volume anomaly of the real sections, we compare the baroclinic transports 
TABLE 2. Ballasting results for upper NAC floats, where $\delta$ is the specific volume anomaly of the float and $\varepsilon \delta_{\text {float }}$ is the ballasting error. The mean $\left(\overline{\delta_{\text {float }}}\right)$ and standard deviation $\left[\sigma\left(\delta_{\text {float }}\right)\right]$ of the specific volume anomaly of the floats are $22.2 \times 10^{-8} \mathrm{~m}^{3} \mathrm{~kg}^{-1}$ and $12.3 \times 10^{-8} \mathrm{~m}^{3}$ $\mathrm{kg}^{-1}$, respectively. Floats 270, 273, 274, 279, 287, 325, 336, and 348 had no CTD cast taken at deployment; hence, their specific volume anomaly and ballast error correspond to $\delta_{\text {float }}$ and $\sigma\left(\delta_{\text {float }}\right)$, respectively.

\begin{tabular}{|c|c|c|c|c|c|}
\hline Float no. & $\delta\left(10^{-8} \mathrm{~m}^{3} \mathrm{~kg}^{-1}\right)$ & $\varepsilon \delta_{\text {float }}\left(10^{-8} \mathrm{~m}^{3} \mathrm{~kg}^{-1}\right)$ & Float no. & $\delta\left(10^{-8} \mathrm{~m}^{3} \mathrm{~kg}^{-1}\right)$ & $\varepsilon \delta_{\text {float }}\left(10^{-8} \mathrm{~m}^{3} \mathrm{~kg}^{-1}\right)$ \\
\hline 252 & 10.7 & 1.0 & 301 & 33.2 & 3.1 \\
\hline 259 & 15.9 & 21.7 & 303 & 10.3 & 4.7 \\
\hline 260 & 11.0 & 1.1 & 304 & 50.0 & 0.9 \\
\hline 261 & 8.5 & 2.3 & 305 & 46.4 & 1.3 \\
\hline 262 & 2.1 & 2.2 & 308 & 49.1 & 1.2 \\
\hline 263 & 17.0 & 1.6 & 310 & 36.0 & 2.6 \\
\hline 264 & 16.1 & 3.2 & 312 & 10.4 & 5.0 \\
\hline 266 & 1.4 & 5.4 & 313 & 32.4 & 2.4 \\
\hline 267 & 8.2 & 2.0 & 316 & 23.0 & 1.9 \\
\hline 275 & 18.0 & 1.9 & 318 & 41.7 & 3.2 \\
\hline 276 & 13.6 & 0.7 & 322 & 16.6 & 6.3 \\
\hline 280 & 5.9 & 2.6 & 324 & 21.7 & 2.9 \\
\hline 283 & 7.9 & 1.8 & 328 & 23.1 & 2.5 \\
\hline 284 & 23.3 & 2.4 & 329 & 20.2 & 0.9 \\
\hline 286 & 28.6 & 1.5 & 330 & 31.9 & 2.1 \\
\hline 288 & 25.8 & 6.8 & 335 & 26.6 & 1.4 \\
\hline 289 & 38.0 & 1.8 & 340 & 20.1 & 4.0 \\
\hline 291 & 5.5 & 6.7 & 344 & 21.7 & 1.3 \\
\hline 292 & 36.1 & 2.7 & 345 & 28.0 & 2.0 \\
\hline 293 & 32.3 & 3.3 & 349 & 24.7 & 1.9 \\
\hline 294 & 14.7 & 2.9 & 351 & 24.8 & 2.7 \\
\hline
\end{tabular}

associated with them. We estimate the volume transport relative to $1000 \mathrm{dbar}(Q)$ as follows:

$$
Q=\int_{0}^{L} \int_{0 \mathrm{dbar}}^{1000 \mathrm{dbar}} V(p, X) d p d x
$$

where

$$
\begin{aligned}
& V(p, X)=\frac{1}{f} \frac{\partial \Phi(p, X)}{\partial x}, \\
& \Phi(p, X)=-\int_{1000 \mathrm{dbar}}^{p} \delta\left(p^{\prime}, X\right) d p^{\prime},
\end{aligned}
$$

$L$ is the length of the transect, $x$ is distance along the transect, $V$ is the baroclinic velocity across the section (referenced to $1000 \mathrm{dbar}$ ), $f$ is the Coriolis parameter, and $\Phi$ is dynamic height (referenced to $1000 \mathrm{dbar}$ ).

For the float-GEM-generated sections, we obtain the profiles of dynamic height at each station from Eq. (1).

The real sections have transports of $Q_{\text {real }}=24 \mathrm{~Sv}(1$ $\mathrm{Sv} \equiv 10^{6} \mathrm{~m}^{3} \mathrm{~s}^{-1}$ ) to the north (NAC), and $Q_{\text {real }}=11$ $\mathrm{Sv}$ to the east (SPF), relative to 1000 dbar. The corresponding transports for the float-GEM sections are $Q_{\mathrm{fg}}$ $\pm \varepsilon Q_{\mathrm{fg}}=23 \pm 2 \mathrm{~Sv}$ for the NAC and $Q_{\mathrm{fg}} \pm \varepsilon Q_{\mathrm{fg}}=$ $13 \pm 1 \mathrm{~Sv}$ for the SPF. Note that the confidence interval $\pm \varepsilon Q_{\mathrm{fg}}$ of the float-GEM estimate $Q_{\mathrm{fg}}$ for the NAC trans-

TABLE 3. Ballasting results for lower NAC floats, where $\delta$ is the specific volume anomaly of the float and $\varepsilon \delta_{\text {float }}$ is the ballasting error. The mean $\left(\overline{\delta_{\text {float }}}\right)$ and standard deviation $\left(\sigma\left(\delta_{\text {float }}\right)\right)$ of the specific volume anomaly of the floats are $-6.2 \times 10^{-8} \mathrm{~m}^{3} \mathrm{~kg}^{-1}$ and $15.5 \times 10^{-8}$ $\mathrm{m}^{3} \mathrm{~kg}^{-1}$, respectively. Floats 254, 265, 269, 297, and 347 had no CTD cast taken at deployment; hence, their specific volume anomaly and ballast error correspond to $\overline{\delta_{\text {float }}}$ and $\sigma\left(\delta_{\text {float }}\right)$, respectively.

\begin{tabular}{cccccc}
\hline \hline Float no. & $\delta\left(10^{-8} \mathrm{~m}^{3} \mathrm{~kg}^{-1}\right)$ & $\varepsilon \delta_{\text {float }}\left(10^{-8} \mathrm{~m}^{3} \mathrm{~kg}^{-1}\right)$ & Float no. & $\delta\left(10^{-8} \mathrm{~m}^{3} \mathrm{~kg}^{-1}\right)$ & $\varepsilon \delta_{\text {float }}\left(10^{-8} \mathrm{~m}^{3} \mathrm{~kg}^{-1}\right)$ \\
\hline 253 & -28.9 & 1.5 & 309 & -2.7 & 2.0 \\
255 & -30.4 & 0.5 & 311 & 8.6 & 2.0 \\
256 & -24.1 & 5.5 & 314 & -19.5 & 2.2 \\
257 & -13.0 & 1.4 & 315 & -7.6 & 3.2 \\
258 & -18.0 & 0.4 & 320 & 6.3 & 4.1 \\
268 & -23.2 & 2.3 & 321 & 0.2 \\
272 & -17.7 & 1.4 & 323 & 2.6 & 2.7 \\
277 & -22.8 & 0.5 & 326 & -7.0 & 1.4 \\
282 & -10.2 & 1.4 & 331 & -3.2 & 3.2 \\
285 & 1.4 & 0.8 & 332 & 0.2 & 3.6 \\
295 & -15.1 & 2.3 & 333 & 0.4 & 1.3 \\
296 & 2.3 & 0.3 & 334 & -0.5 & 4.3 \\
298 & -15.1 & 7.0 & 337 & -8.2 & 2.8 \\
300 & -8.8 & 3.5 & 339 & 55.5 & 2.3 \\
306 & -1.9 & 1.7 & 341 & & \\
307 & 12.4 & 4.8 & 342 & & \\
\hline
\end{tabular}


TABLE 4. Ballasting results for ACCE floats, where $\delta$ is the specific volume anomaly of the float and $\varepsilon \delta_{\text {float }}$ is the ballasting error. All floats had a CTD cast taken at deployment. The mean specific volume anomaly of the floats $\overline{\delta_{\text {float }}}=-4.1$, with a standard deviation of $\sigma\left(\delta_{\text {float }}\right)=5.8$.

\begin{tabular}{|c|c|c|c|c|c|}
\hline Float no. & $\delta\left(10^{-8} \mathrm{~m}^{3} \mathrm{~kg}^{-1}\right)$ & $\varepsilon \delta_{\text {float }}\left(10^{-8} \mathrm{~m}^{3} \mathrm{~kg}^{-1}\right)$ & Float no. & $\delta\left(10^{-8} \mathrm{~m}^{3} \mathrm{~kg}^{-1}\right)$ & $\varepsilon \delta_{\text {float }}\left(10^{-8} \mathrm{~m}^{3} \mathrm{~kg}^{-1}\right)$ \\
\hline 438 & -15.2 & 0.7 & 544 & -3.3 & 1.5 \\
\hline 440 & -17.1 & 0.6 & 546 & -5.1 & 2.6 \\
\hline 448 & -10.5 & 1.3 & 547 & -3.6 & 0.5 \\
\hline 453 & -3.8 & 3.6 & 548 & -2.4 & 0.7 \\
\hline 459 & -2.8 & 0.5 & 549 & -6.1 & 1.4 \\
\hline 466 & -8.6 & 0.3 & 550 & 0.1 & 2.7 \\
\hline 469 & -8.7 & 1.3 & 552 & -0.7 & 1.2 \\
\hline 475 & -9.5 & 0.4 & 553 & -3.1 & 1.8 \\
\hline 476 & -13.4 & 1.3 & 554 & 1.7 & 0.4 \\
\hline 479 & -16.5 & 0.5 & 557 & 4.5 & 2.5 \\
\hline 480 & -12.5 & 0.5 & 558 & 3.5 & 0.5 \\
\hline 497 & -4.9 & 0.7 & 559 & 6.4 & 0.3 \\
\hline 502 & -6.8 & 0.5 & 560 & -0.6 & 1.3 \\
\hline 510 & 1.9 & 0.4 & 561 & -11.8 & 0.5 \\
\hline 530 & -5.7 & 0.7 & 563 & -6.1 & 1.4 \\
\hline 531 & -5.6 & 0.7 & 564 & -6.7 & 1.0 \\
\hline 534 & -9.0 & 0.6 & 566 & 4.0 & 4.7 \\
\hline 535 & -3.0 & 0.3 & 569 & -0.4 & 0.9 \\
\hline 536 & 1.6 & 2.3 & 570 & -1.5 & 2.2 \\
\hline 537 & 3.1 & 1.0 & 571 & 1.6 & 0.7 \\
\hline 538 & 0.3 & 0.6 & 572 & -7.5 & 1.4 \\
\hline 539 & -7.5 & 3.1 & 573 & -0.1 & 1.5 \\
\hline 540 & 5.6 & 0.9 & 574 & -9.3 & 1.5 \\
\hline 541 & 1.5 & 0.4 & 575 & -1.4 & 0.5 \\
\hline 542 & -1.1 & 1.3 & 576 & -9.8 & 2.4 \\
\hline
\end{tabular}

port contains the "real" NAC value, while the SPF transport is overestimated by $10 \%$. For a discussion on how we calculate the confidence intervals for the transport estimates, refer to the appendix.

We define the accuracy of the float-GEM estimates as

$$
\text { accuracy }=\frac{\left|Q_{\text {real }}-Q_{\mathrm{fg}}\right|}{Q_{\text {real }}} \times 100 \%,
$$

and the precision is given by

$$
\text { precision }=\frac{\varepsilon Q_{\mathrm{fg}}}{Q_{\mathrm{fg}}} \times 100 \% .
$$

Hence, the simulated mass transport for the NAC has an accuracy of $\pm 4 \%$ and a precision of $\pm 9 \%$, while the SPF estimate has an accuracy of $\pm 18 \%$ and a precision of $\pm 8 \%$.

Having the temperature $(T)$ and baroclinic velocities $(V)$, the temperature transport for the top $1000 \mathrm{dbar}(H)$ can be calculated:

$$
H=\int_{0}^{L} \int_{0 \mathrm{dbar}}^{1000 \mathrm{dbar}} \rho C_{p} V(p, X) T(p, X) d p d x,
$$

where $\rho$ is the in situ density and $C_{p}$ is the specific heat capacity of seawater. The product $\rho C_{p}$ is assumed constant $\left(4000 \times 10^{3} \mathrm{~J} \mathrm{~m}^{-3} \mathrm{~K}^{-1}\right)$.

The real NAC section has a transport of $H_{\text {real }}=-1.23$ PW, while the SPF transports $H_{\text {real }}=0.39 \mathrm{PW}$ (relative to $1000 \mathrm{dbar}$ ). The corresponding estimates for the floatGEM sections are $H_{\mathrm{fg}} \pm \varepsilon H_{\mathrm{fg}}=1.03 \pm 0.15 \mathrm{PW}$ and
$H_{\mathrm{fg}} \pm \varepsilon H_{\mathrm{fg}}=0.42 \pm 0.03 \mathrm{PW}$, respectively. The calculation of the confidence interval $\pm \varepsilon H_{\mathrm{fg}}$ for the floatGEM temperature transport estimate $H_{\mathrm{fg}}$ is described in the appendix. The float-GEM estimate for both sections deviates less than 5\% from the real value. The accuracy of the float-GEM temperature transport estimates is $\pm 16 \%$ for the NAC and $\pm 8 \%$ for the SPF, while the precision is $\pm 15 \%$ and $\pm 7 \%$ for the NAC and SPF, respectively.

In conclusion, the float-GEM transport estimates have an accuracy of $\pm 20 \%$ (or less) when used to reproduce synoptic sections. Given a precision of $\pm 15 \%$ (or less) results in the real values deviating less than $\pm 10 \%$ from the float-GEM estimates. Considering that the float-GEM-generated hydrographic profiles are climatological ones, it is quite striking how well the baroclinic transports are reproduced across those sections. This gives confidence in using the method to make mean transport estimates, especially if good float coverage for the region is available.

\section{Consistency check: Horizontal maps using real float data}

Carr et al. (1997) use RAFOS float data from the NAC experiment (section $3 \mathrm{a}$ ) to construct the pressure of the $\delta_{\text {target }}=-12.7 \times 10^{-8} \mathrm{~m}^{3} \mathrm{~kg}^{-1}$ surface (target isopycnal for the deep NAC floats). To project all the float data on the same surface, they correct each float for the error in pressure due to uncertainty in float ballasting. They then take the median of the data on each 


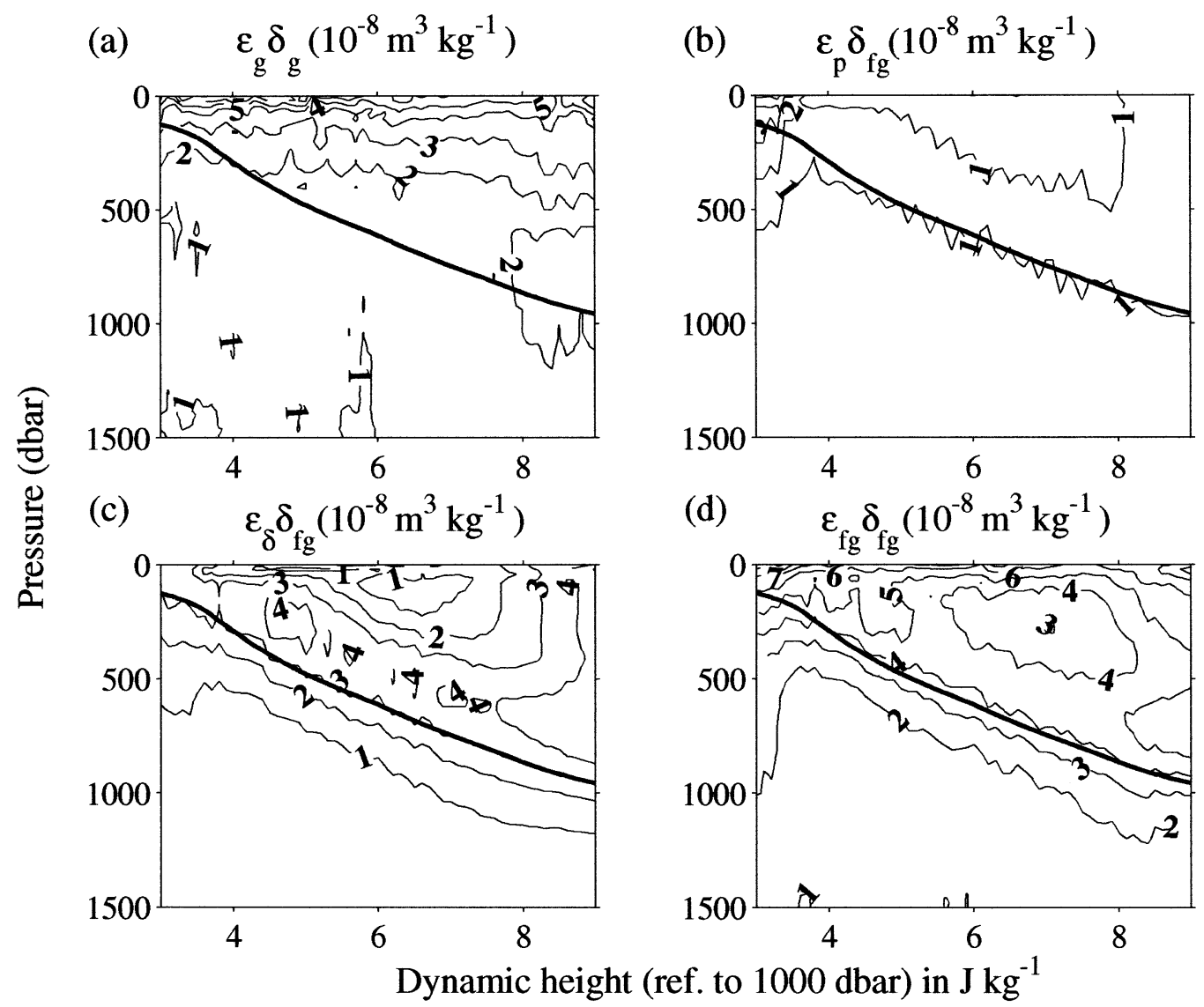

FIG. 7. Float-GEM errors for the specific volume anomaly in subregion 1. (a) GEM mean-square error, (b) error due to uncertainty in float pressure, (c) error associated with float ballasting uncertainty, and (d) the total float-GEM error. The bold line indicates the surface where the specific volume anomaly is $\delta_{\text {float }}=-12.7 \times 10^{-8} \mathrm{~m}^{3} \mathrm{~kg}^{-1}$.

bin of a $0.5^{\circ} \times 0.5^{\circ}$ grid, and fit a bicubic smoothing spline surface to obtain the maps shown in Fig. 10a. Similarly, using the float temperature data, and correcting that for the error in float ballasting, they obtain the float-derived temperature of the same target specific volume anomaly surface (Fig. 11a).

In the same article, Carr et al. (1997) show the climatological temperature on $\delta_{\text {target }}$ (Fig. 11b), calculated from historical bottle data following the same gridding and interpolating procedure as for the float-derived map.

Using historical hydrography, Carr et al. (1997) find a strong correlation between the depth of the $\delta_{\text {target }}=$ $-12.7 \times 10^{-8} \mathrm{~m}^{3} \mathrm{~kg}^{-1}$ and potential energy anomaly ( $\chi)$ relative to 2000 dbar:

$$
\chi=-\frac{1}{g} \int_{2000 \mathrm{dbar}}^{0 \mathrm{dbar}} p \delta d p,
$$

where $g$ is the acceleration of gravity. The baroclinic transport between two geographical points is given by the difference in the potential energy anomaly between the points, divided by the Coriolis parameter. Kearns (1996) also finds a strong correlation with the transport potential relative to $1000 \mathrm{dbar}$. Using the pressure record from 68 NAC floats and the aforementioned historical relationship, Kearns (1996) obtains the float-derived transport potential, applying the same interpolating and mapping procedure as was used by Carr et al. (1997). The resulting map is shown in Fig. 12a.

To check the consistency of the float-GEM method, we use all the float data from the NAC and ACCE experiments, and calculate with the technique the pressure and temperature on the target specific volume anomaly surface used in Carr et al. (1997), as well as the transport potential relative to 1000 dbar.

Since each float is associated with a slightly different specific volume anomaly, the cutoff temperature needed to distinguish between the two modes of the temperature GEM field in the NAC region would, in principle, be different for each float. By looking at histograms of temperature for the range of the actual $\delta$ surfaces sampled by the NAC and ACCE floats (see Tables 2-4), and the distribution of temperature versus streamfunction for each of those $\delta$ surfaces, we conclude that $3.5^{\circ} \mathrm{C}$ effectively delimits the two modes of the temperature GEM field for the range of $\delta$ samples by the floats.

For each float station, the full profiles of specific vol- 


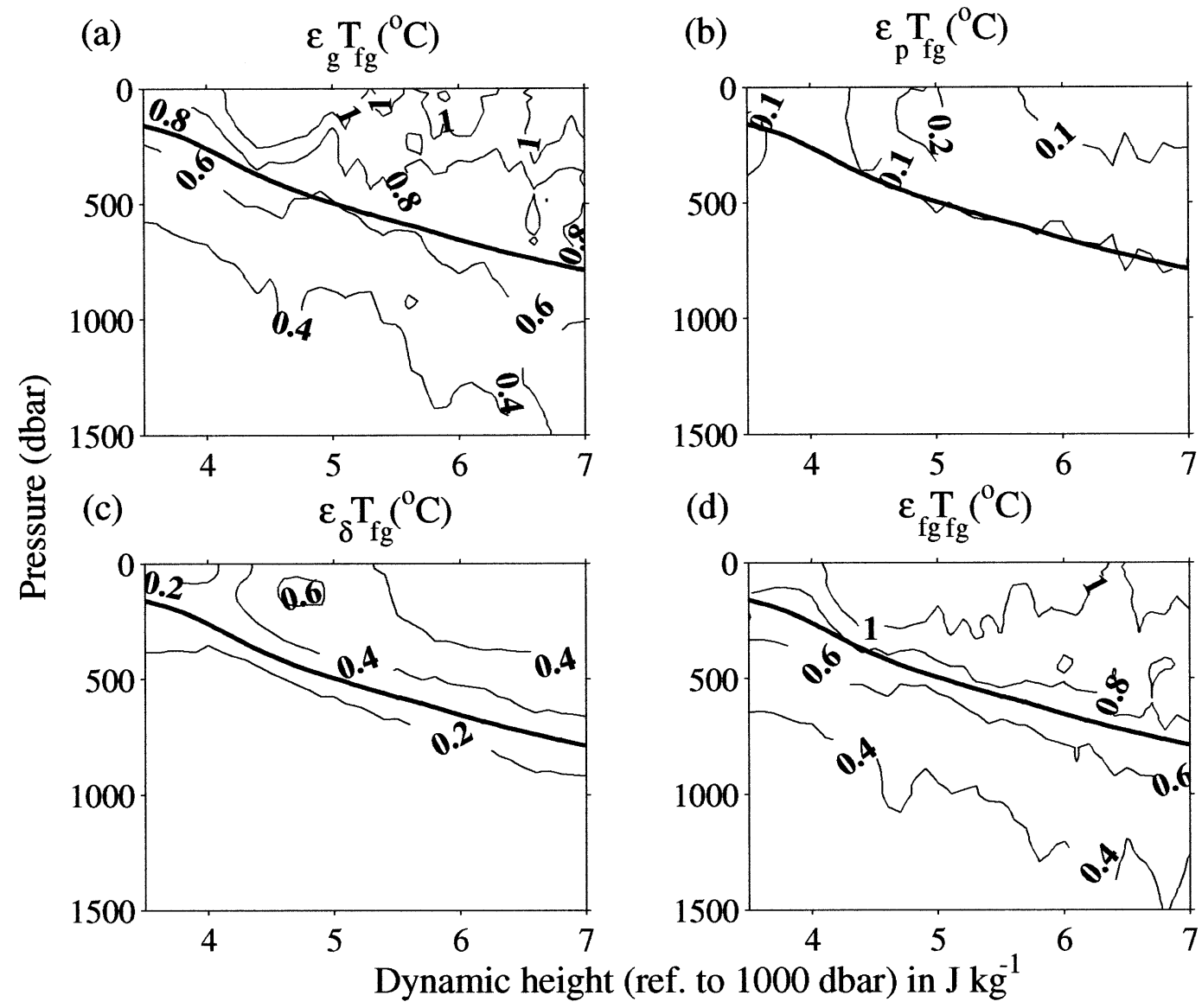

FIG. 8. Float-GEM errors for temperature in subregion 4. See Fig. 7 for details.

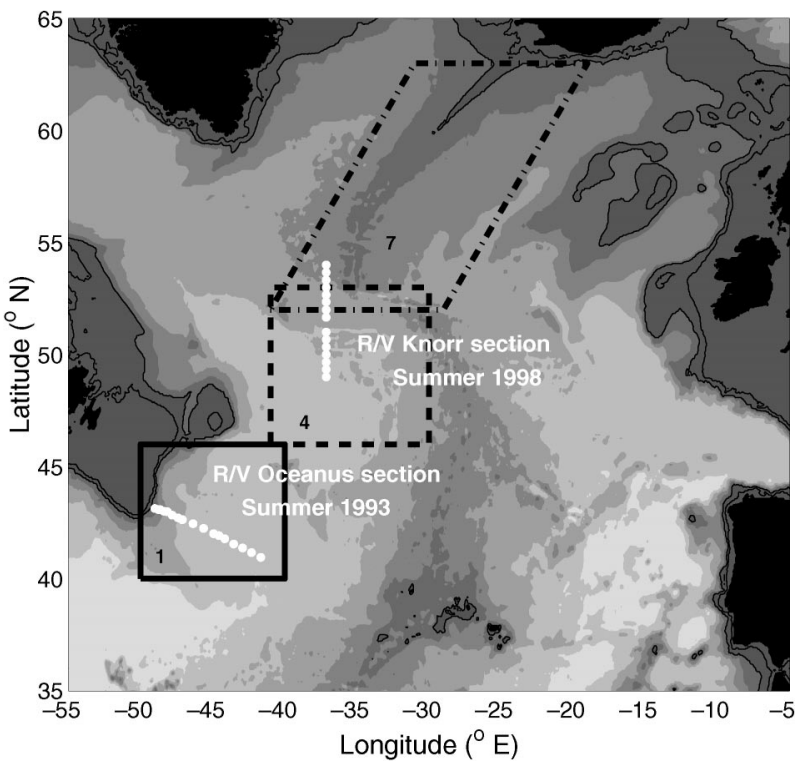

FIG. 9. CTD transects across the NAC (R/V Oceanus, Aug 1993) and SPF (R/V Knorr, Jul 1998), used to test the float-GEM technique. The GEM fields used correspond to subregions 1, 4, and 7 containing the CTD transects. ume anomaly and temperature are obtained, using the day of the year GEM fields constructed in Pérez-Brunius (2002) and PRW, as described in section 2. We then calculate the depth of $\delta_{\text {target }}$ at each station, by linearly interpolating the specific volume anomaly profile. Having the depth of the target surface at a given station, the corresponding temperature is obtained from the station's temperature GEM profile. The potential energy anomaly is derived from the specific volume anomaly profiles using Eq. (18).

We create horizontal maps for each season, separating the float stations in bins 3 months long, centered on March (spring), June (summer), September (fall), and December (winter). The data are mapped onto a $0.5^{\circ} \times$ $0.5^{\circ}$ grid with optimal interpolation, using a Gaussian correlation function. To save computer time, only data points within a $5^{\circ}$ window around the grid point are used in the interpolation. Since optimal interpolation applies only to variables with zero mean, we have to remove a mean field from the data, and apply the method to the residuals. The final field is the mean field plus the optimally interpolated residual field. To obtain the mean field, a first pass of the optimal interpolation is applied to the raw data, using a correlation length scale of $150 \mathrm{~km}$, following Watts et al. (2001). We substract 
(a)

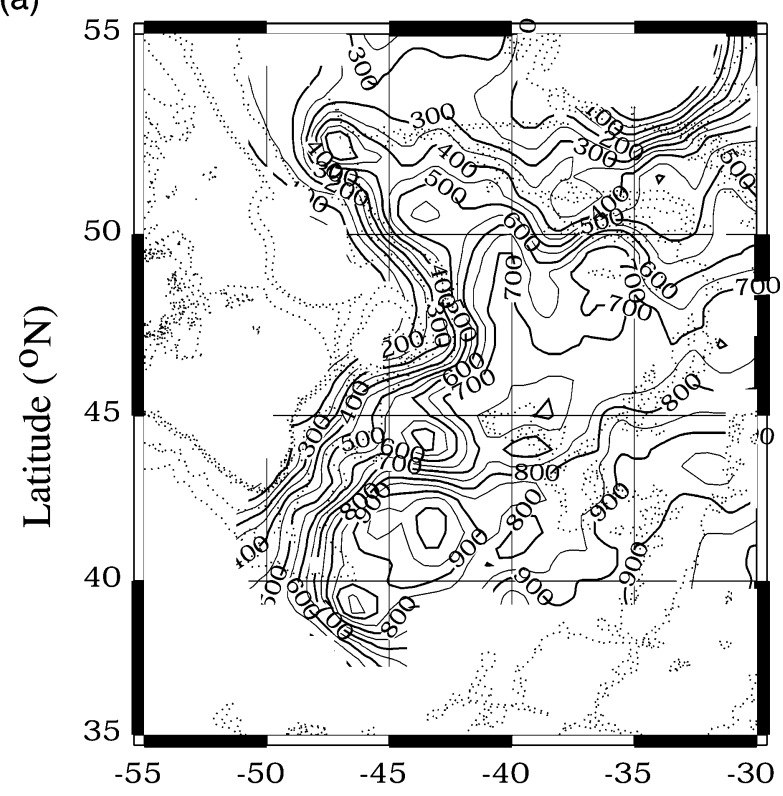

(b)

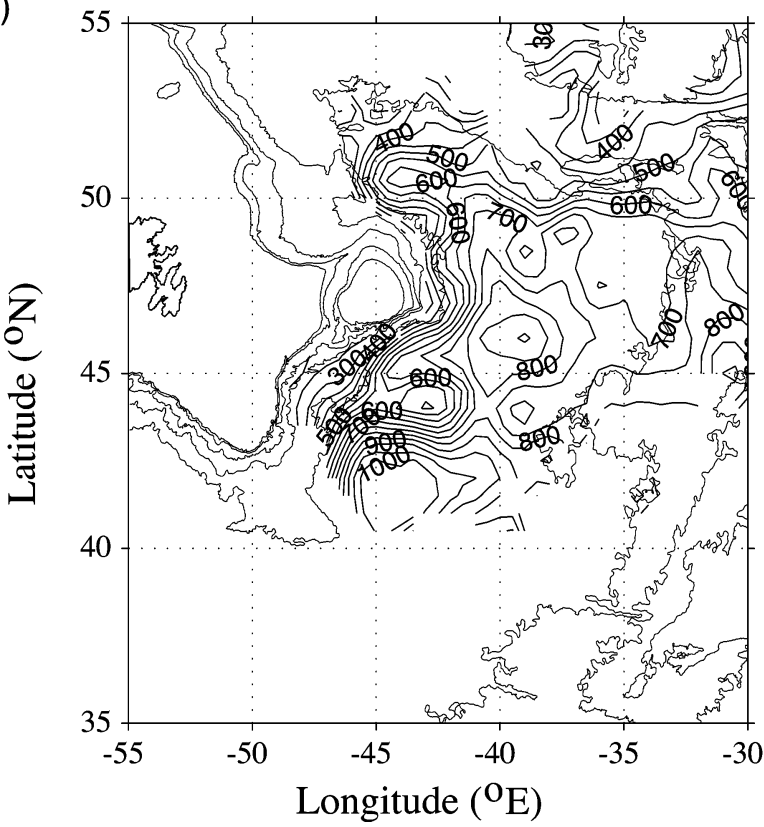

FIG. 10. Pressure (dbar) of the $-12.7 \times 10^{-8} \mathrm{~m}^{3} \mathrm{~kg}^{-1}$ specific volume anomaly surface obtained from (a) the deep floats of the NAC experiment (Carr et al. 1997, Fig. 4a) and (b) applying the floatGEM technique to the NAC and ACCE float data. Contour interval is $50 \mathrm{dbar}$.

the mean field from the data, and apply the optimal interpolation procedure to the residuals, using a correlation length scale of $90 \mathrm{~km}$. The seasonal maps result from adding the residual field to the mean field. The mean is taken over the four seasons to ensure that all seasons have approximately equal weights for the annual mean. The final mean pressure, temperature, and transport potential maps are shown in Figs. 10b, 11c, and $12 \mathrm{~b}$, respectively. Only grid points for which the error in the objective mapping is less than $50 \%$ are shown. Note that we chose $90 \mathrm{~km}$ as the approximate correlation length scale for the optimal interpolation of the residual fields. This corresponds to the approximate zero crossing of the correlation function for this region, as obtained from altimeter data by Stammer (1997).

The depth of $\delta_{\text {target }}=-12.7 \times 10^{-8} \mathrm{~m}^{3} \mathrm{~kg}^{-1}$ obtained with the float-GEM technique compares well with the corresponding map produced by Carr et al. (1997) (Fig. 10). The largest differences occur in the region where the SPF crosses the Mid-Atlantic Ridge, and in the Mann Eddy. The region near the crossing of the SPF over the Mid-Atlantic Ridge is where both the NAC and ACCE float data overlap, while it is the limit of the extent of the NAC data used by Carr et al. (1997). This may account for the difference. In addition, Carr et al. (1997) only used the lower NAC floats, while both the upper and lower floats were used for the float-GEM-derived maps, resulting in higher coverage for the Mann Eddy region. This may explain why the structure of the Mann Eddy seems more regular for the float-GEM-generated map than for the one created by Carr et al. (1997). Also, the interpolating techniques are rather different; hence, small differences are to be expected. Note how both maps show a distinctive trough (or eastward meander) of the NAC at $44^{\circ} \mathrm{N}$. This feature has been observed in other studies (LaViolette 1983; Krauss 1986) and was particularly extended to the east during the time period sampled by the NAC floats (Carr et al. 1997; Kearns and Rossby 1998).

The float-GEM-produced map of temperature on $\delta_{\text {target }}$ is harder to compare to the corresponding maps generated by Carr et al. (1997) (Figs. 11a-c). The reason is that the float-GEM temperature profiles are obtained from the GEM projections of the historical hydrographic data, while the spatial distribution of the temperature field is given by the float stations (Fig. 11c). On the other hand, the climatological map of Fig. 11b corresponds to an Eulerian average of the historical hydrography, while the float-derived map of Fig. 11a is derived from the actual temperature measured by the floats. We would expect the float-GEM map to better compare to the climatological one, since the small-scale features captured by the actual measurements of temperature of the floats would be filtered out with the float-GEM technique. This is evident in Figs. 11b and 11c, which show patterns and actual values that are generally the same. The exception is found on the trough of the NAC at $44^{\circ} \mathrm{N}$, which is not present in the climatological map. Note that the map constructed with the actual temperature of the floats shows this trough, having the same extension as the one in the float-GEM map.

Finally, the transport potential map constructed with the float-GEM technique shows the same basic pattern and transports as the map produced by Kearns (1996) (Fig. 12). The major difference is found in the Northwest 

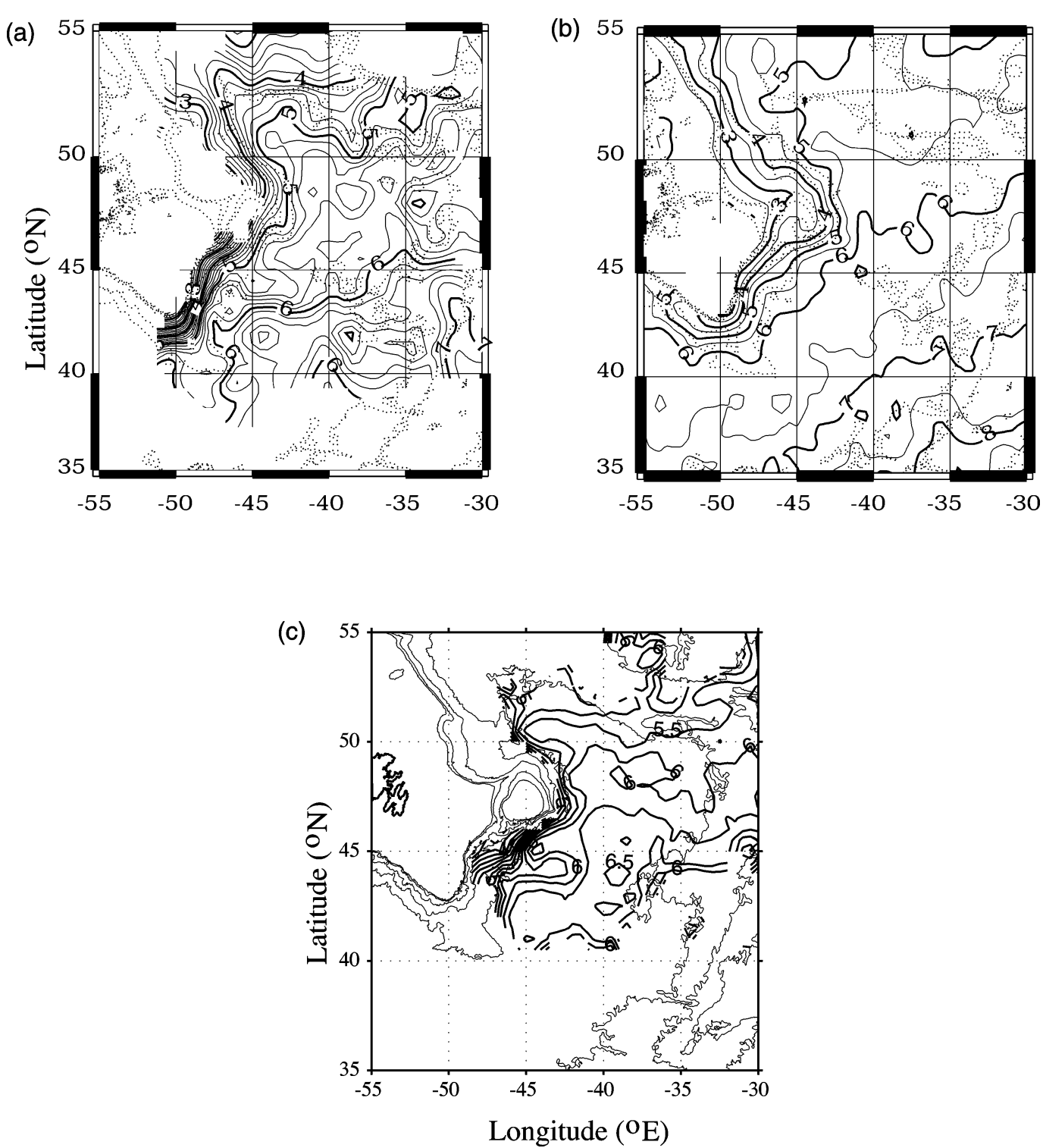

FIG. 11. (a) Temperature $\left({ }^{\circ} \mathrm{C}\right)$ on the $-12.7 \times 10^{-8} \mathrm{~m}^{3} \mathrm{~kg}^{-1}$ specific volume anomaly surface, obtained from the temperature data measured by the deep floats of the NAC experiment (Carr et al. 1997, Fig. 4b). (b) Climatological temperature $\left({ }^{\circ} \mathrm{C}\right)$ on the $-12.7 \times 10^{-8} \mathrm{~m}^{3} \mathrm{~kg}^{-1}$ specific volume anomaly surface obtained from $40 \mathrm{yr}$ of historical bottle data (Carr et al. 1997, Fig. 3b). (c) Temperature of $\delta=-12.7 \times 10^{-8} \mathrm{~m}^{3} \mathrm{~kg}^{-1}$ obtained by applying the floatGEM technique to the NAC and ACCE float data. Contour interval is $0.25^{\circ} \mathrm{C}$.

Corner, where the float-GEM map shows a more pronounced loop than the map derived in Kearns (1996).

In conclusion, the float-GEM maps agree well with similar maps found in the literature, even though they are constructed in very different ways. The differences found between either the Carr et al. (1997) or Kearns (1996) maps and the float-GEM maps are small considering that the interpolating and averaging routines used are different in each of the studies. Another reason that may account for the differences, especially in the SPF region, is that we use two datasets covering a much longer time period (1993-2000), instead of only the deep NAC floats (1993-95) as in Carr et al. (1997) and Kearns (1996).

\section{Conclusions}

The float-GEM technique presented in this paper serves as a good tool for obtaining information on the vertical structure of the mean three-dimensional hydrographic field, for the region and time period covered by the isopycnal float experiment in question. It should be noted that the method can be extended to isobaric floats, provided that the specific volume anomaly at each data 

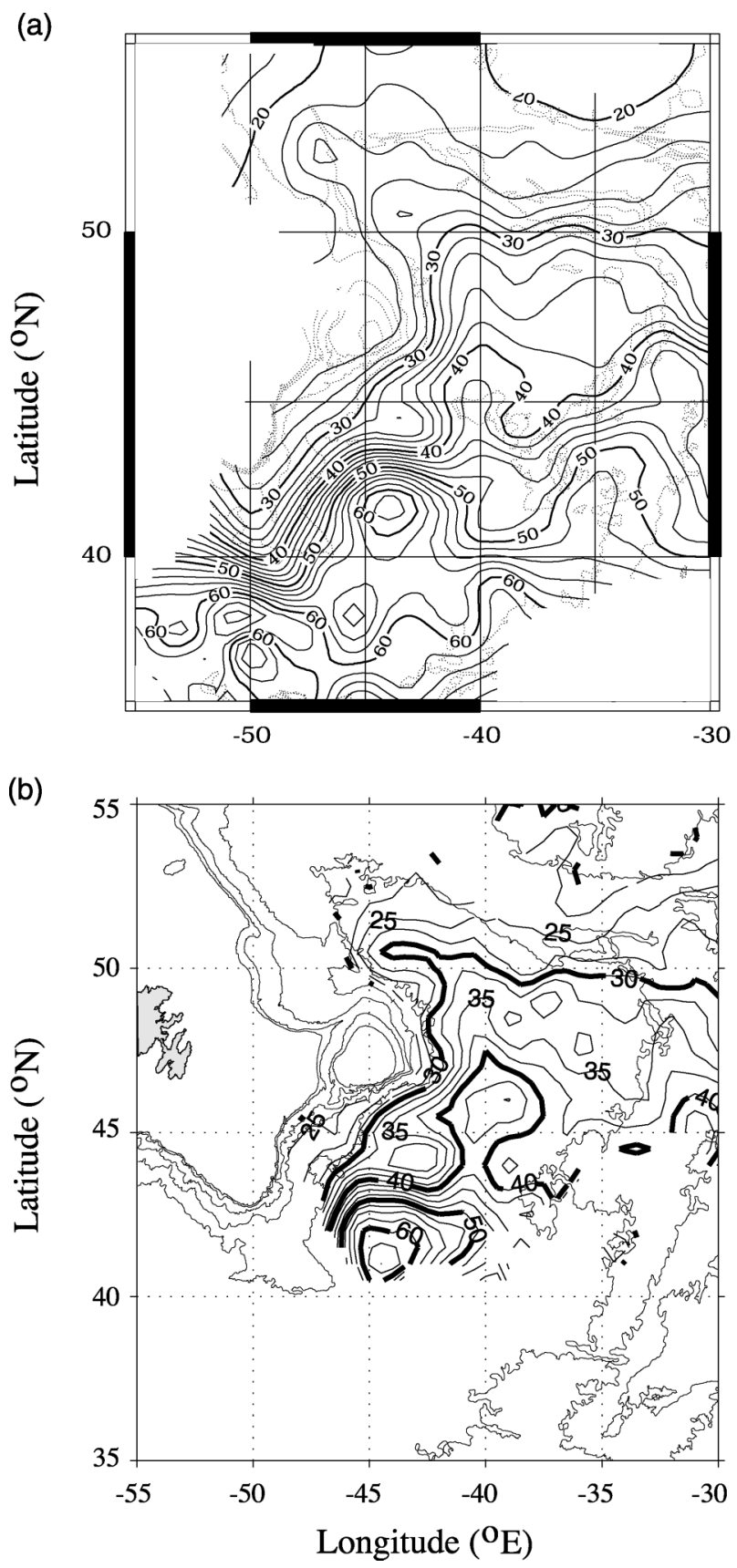

FIG. 12. Transport potential (relative to 1000 dbar) obtained from (a) 68 NAC floats' pressure records (Kearns 1996, Fig. 45) and (b) applying the float-GEM technique to the NAC and ACCE float data. The difference between contour values is a measure of the mass transport between those contours (in $10^{9} \mathrm{~kg} \mathrm{~s}^{-1} \approx 1 \mathrm{~Sv}$ ). Contour interval is $2 \mathrm{~Sv}$.

point can be determined. This can be accomplished using the method presented by Boebel et al. (1995), where the density at each data point is obtained from the float's pressure and temperature records, and the mechanical properties of the float.

We tested the technique for the northern North At- lantic, by reconstructing two CTD transects with simulated float data: one across the NAC near $42^{\circ} \mathrm{N}$, the other across the SPF along $37^{\circ} \mathrm{W}$. The float-GEM technique reproduces well the baroclinic transports of volume and temperatures across the CTD transects (deviations from the values obtained from the actual observations were $10 \%$ or less). Hence, the technique looks promising in making such estimates in regions where there is good float data coverage.

We also checked the consistency of the method, by using real float data to construct horizontal maps of temperature and depth of the $\delta=-12.7 \times 10^{-8} \mathrm{~m}^{3}$ $\mathrm{kg}^{-1}\left(\sim \sigma_{\theta}=27.5 \mathrm{~kg} \mathrm{~m}^{-3}\right)$ surface, as well as the transport potential $\left(f^{-1} \chi\right.$, relative to $\left.1000 \mathrm{dbar}\right)$, for the northern North Atlantic. Similar maps were constructed by Kearns (1996) and Carr et al. (1997), using a different method with a subset of the float data used for the floatGEM maps. The float-GEM maps compare well with the maps in the literature, the differences being small considering that both the hydrographic and float data used are for different time periods and experiments, and the methodology and interpolating routines differ substantially.

The positive results from both tests suggest that the float-GEM technique can be successfully used with the NAC and ACCE float data, to obtain estimates of the baroclinic transports for the NAC-SPF system. Also note that the methodology includes error estimation, a valuable resource that provides confidence intervals for the estimates obtained by the method.

In principle, absolute transports can be estimated with this technique, by making use of the velocity data measured by the floats. Pérez-Brunius (2002) and PérezBrunius et al. (2003a, manuscript submitted to J. Phys. Oceanogr.) use this application to estimate the absolute transports of mass and temperature for the top $1000 \mathrm{dbar}$ in the NAC-SPF system. Moreover, they are able to quantify the heat lost by the current on its transit toward the subpolar North Atlantic. One could question the utility of the float-GEM technique for estimating absolute transports in other regions, now that profiling floats such as (profiling) autonomous Lagrangian circulation explores [(P) ALACE information online at http://hrp.whoi.edu/floats/spalace_overv.html] and Argo (information online at http://www.argo.ucsd.edu) are currently sampling the ocean with that purpose. The advantage of using acoustically tracked floats instead of profiling floats is that the velocity at the parking level is more accurately measured by the former: the velocity measured by profiling floats is an average over time between fixes (usually 10 days), while most of the acoustically tracked floats obtain their fixes at least once a day. In addition, profiling floats tend to bias their velocity estimates in regions of high vertical shear (Ichikawa et al. 2001). Even though profiling floats are distributed over all the major oceans, isobaric/isopycnal float experiments can result in higher spatial coverage for certain oceanic regions. In this sense, the float-GEM 
method can be of use as an independent estimate for comparison with results obtained through other means (e.g., profiling floats) in regions where acoustically tracked floats are available.

The float-GEM technique proves to be a powerful tool that allows float data to be used as hydrographic "profilers" and "current meters" at the same time. This can in turn be used to estimate the three-dimensional structure of the hydrographic field and the mean absolute transports for large regions. The Gulf Stream, and Brazil and Agulhas Currents, are ocean currents for which acoustically tracked floats are currently available and, hence, could be studied with the floatGEM approach [for the distribution of Sound Fixing and Ranging (SOFAR), inverse of SOFAR (RAFOS), and multicycle RAFOS (MARVOR) float data, see the WOCE Subsurface Data Assembly Center Web page: http://wfdac.whoi.edu/table.htm]. Examples of hydrographic data sources for the construction of the GEM fields are HydroBase (http://www.whoi.edu/science/ PO/hydrobase/), the WOCE Hydrographic Program Office (http://whpo/ucsd.edu/), and the profiles from Argo floats (http://www-argo.ucsd.edu/).

Acknowledgments. The authors would like to thank Jim Fontaine for building the floats, Sandra AndersonFontana for tracking them, and Peter Lazarevich, Mark Prater, and Huai-Min Zhang for subsequent data analysis and helpful discussions. Byron Willeford and Karen Tracey gave good tips for the GEM construction and horizontal mapping of the fields. Mark Prater, Mark Wimbush, and Tim Fristedt provided helpful suggestions for improving this manuscript. We greatly appreciate the comments of three anonymous reviewers. This research was supported by the U.S. National Science Foundation under Grant OCE 99-06775. Paula Pérez-Brunius was supported via a graduate fellowship provided by the Consejo Nacional de Ciencia y Tecnología, México, and a Fulbright-García Robles grant.

\section{APPENDIX}

\section{Float-GEM Transport Errors}

\section{a. Volume transport errors}

Since the variables we use are discrete, we estimate the integrals and derivatives of Eqs. (12) and (17) as follows:

$$
Q=\sum_{i} \sum_{j} V(i, j) \Delta p(i) \Delta x(j)
$$

where

$$
V(i, j)=\frac{1}{f} \frac{\Delta \Phi(i, j)}{\Delta x(j)},
$$

$Q$ is the volume transport; the indexes $(i, j)$ correspond to vertical and horizontal bins, respectively; $V$ is the baroclinic velocity (referenced to $1000 \mathrm{dbar}$ ); $\Phi$ is the dynamic height (referenced to $1000 \mathrm{dbar}$ ); and $x$ is the distance along the transect. The sums are carried out over the vertical bins between 0 and 1000 dbar, and horizontal bins covering the entire section.

The confidence intervals $\pm \varepsilon Q$ associated with the volume transports estimated with the float-GEM technique are calculated as follows:

$$
(\varepsilon Q)^{2}=\sum_{i}\left[\varepsilon Q_{1}(i) \Delta x(j)\right]^{2},
$$

where

$$
\begin{aligned}
{\left[\varepsilon Q_{1}(i)\right]^{2} } & =\sum_{j}[\varepsilon V(i, j) \Delta p(i)]^{2}, \\
\varepsilon V(i, j) & =\frac{1}{f} \frac{\varepsilon \Delta \Phi(i, j)}{\Delta x(j)}, \\
{[\varepsilon \Delta \Phi(i, j)]^{2} } & =\left[\varepsilon \Phi\left(i, j+\frac{1}{2}\right)\right]^{2}+\left[\varepsilon \Phi\left(i, j-\frac{1}{2}\right)\right]^{2},
\end{aligned}
$$

and $\varepsilon \Phi$ is the float-GEM error associated with dynamic height.

\section{b. Temperature transport errors}

In a related manner, the temperature transport $H$ calculated using Eq. (17) is estimated as follows:

$$
H=\rho C_{p} \sum_{i} \sum_{j} V(i, j) T(i, j) \Delta p(i) \Delta x(j),
$$

where $\rho$ is the mean density of seawater, $C_{p}$ the specific heat of seawater, and $T$ is temperature. The corresponding confidence interval $\pm \varepsilon H$ for the temperature transport estimated with the float-GEM technique is given by

$$
\begin{aligned}
(\varepsilon H)^{2}= & \left(\rho C_{p}\right)^{2} \sum_{i} \sum_{j}[V(i, j) T(i, j) \Delta p(j) \Delta x(i)]^{2} \\
& \times\left\{\left[\frac{\varepsilon V(i, j)}{V(i, j)}\right]^{2}+\left[\frac{\varepsilon T(i, j)}{T(i, j)}\right]^{2}\right\},
\end{aligned}
$$

where $\varepsilon T$ is the float-GEM error of temperature. Equations (A3)-(A8) result from the propagation of errors for sums and products (Emery and Thomson 2001).

\section{REFERENCES}

Anderson-Fontana, S., M. Prater, and H. T. Rossby, 1996: RAFOS float data report of the North Atlantic Current study 1993-1995. GSO Tech. Rep. 96-4, Graduate School of Oceanography, University of Rhode Island, $241 \mathrm{pp}$.

_- P. Lazarevich, P. Perez-Brunius, M. Prater, T. Rossby, and H.M. Zhang, 2001: RAFOS float data report of the Atlantic Climate Change Experiment (ACCE), 1997-2000. GSO Tech. Rep. 014, Graduate School of Oceanography, University of Rhode Island, $112 \mathrm{pp}$.

Belkin, I. M., and S. Levitus, 1996: Temporal variability of the subarctic front near the Charlie-Gibbs Fracture Zone. J. Geophys. Res., 101, 28 317-28 324. 
Boebel, O., K. L. Schultz, and W. Zenk, 1995: Calculation of salinity from neutrally buoyant RAFOS floats. J. Atmos. Oceanic Technol., 12, 923-934.

- R. E. Davis, M. Ollitrault, R. G. Peterson, P. L. Richardson, C. Schmid, and W. Zenk, 1999: The intermediate depth circulation of the western South Atlantic. Geophys. Res. Lett., 26, 3329-3332.

, C. Barron, P. Richardson, J. Lutjeharms, and R. Davis, 2000: Mixing of Antarctic Intermediate Water from the Atlantic and Indian Ocean at the Agulhas Retroflection. International WOCE Newsletter, No. 39, WOCE International Project Office, Southampton, United Kingdom, 9-12.

Book, J. W., M. Wimbush, S. Imawaki, H. Ichikawa, H. Uchida, and H. Kinoshita, 2002: Kuroshio temporal and spatial variations south of Japan determined from inverted echo sounder measurements. J. Geophys. Res., 107, 3121, doi:10.1029/ 2001JC000795.

Bower, A. S., and Coauthors, 2002: Directly measured mid-depth circulation in the northeastern North Atlantic Ocean. Nature, 419, 603-607.

Bubnov, V. S., 1995: The North Atlantic Current by the Atlantex 90 experiment data. Oceanology, 34, 733-737.

Carr, M. E., E. J. Kearns, and H. T. Rossby, 1997: Isopycnal RAFOS floats as roving hydrographers in the North Atlantic Current region. Geophys. Res. Lett., 24, 551-554.

Clarke, R. A., H. W. Hill, R. F. Reiniger, and B. A. Warren, 1980: Current system south and east of the Grand Banks of Newfoundland. J. Phys. Oceanogr., 10, 25-65.

Curry, R. G., 1996: HydroBase-A database for hydrographic stations and tools for climatological analysis. Woods Hole Oceanographic Institution Tech. Rep. WHOI-96-01, 44 pp.

Emery, W. J., and R. E. Thomson, 2001: Data Analysis Methods in Physical Oceanography. 2d ed. Elsevier Science, 638 pp.

Ichikawa, Y., Y. Takatsuki, K. Mizuno, N. Shikama, and K. Takeuchi, 2001: Estimation of drifting velocity and error at parking depth for Argo float. Japan Marine Science Technology Center/Kaiyo Kagaku Gijutsu Senta Shiken Kenkyu Hokoku Tech. Rep. 44, 81-89.

Kearns, E. J., 1996: A description of the North Atlantic Current system from historical hydrography. Ph.D. thesis, University of Rhode Island, $189 \mathrm{pp}$.

—_ and H. T. Rossby, 1998: Historical position of the North Atlantic Current. J. Geophys. Res., 103, 15 509-15 524.

Krauss, W., 1986: The North Atlantic Current. J. Geophys. Res., 91, 5061-5074.

Lavender, K. L., R. E. Davis, and W. B. Owens, 2000: Mid-depth recirculation observed in the interior Labrador and Irminger Seas by direct velocity measurements. Nature, 407, 66-69.

LaViolette, P., 1983: The Grand Banks Experiment: A satellite/air- craft/ship experiment to explore the ability of specialized radars to define ocean fronts. NORDA Tech. Rep. 49, Naval Oceanographic and Atmospheric Research Laboratory, Stennis Space Center, MS, $116 \mathrm{pp}$.

Lazier, J. R. N., 1994: Observations in the northwest corner of the North Atlantic Current. J. Phys. Oceanogr., 24, 1449-1463.

McDougall, T. J., 1987: Neutral surfaces. J. Phys. Oceanogr., 17, 1950-1964.

, 1989: Streamfunctions for the lateral velocity vector in a compressible ocean. J. Mar. Res., 47, 267-284.

Meinen, C. S., and D. R. Watts, 2000: Vertical structure and transport on a transect across the North Atlantic Current near $42^{\circ} \mathrm{N}$ : Time series and mean. J. Geophys. Res., 105, 21 869-21 891.

,-- , and R. A. Clarke, 2000: Absolutely referenced geostrophic velocity and transport on a section across the North Atlantic Current. Deep-Sea Res., 47, 309-322.

Ollitrault, M., 1999: MARVOR floats reveal intermediate circulation in the western equatorial and tropical South Atlantic $\left(30^{\circ} \mathrm{S}\right.$ to $\left.5^{\circ} \mathrm{N}\right)$. International WOCE Newsletter, No. 34, WOCE International Project Office, Southampton, United Kingdom, 7-10.

Pérez-Brunius, P., 2002: The North Atlantic Current-Subpolar front system: A study combining float data and historical hydrography. Ph.D. thesis, University of Rhode Island, 165 pp.

Rossby, T., 1999: On gyre interactions. Deep-Sea Res., 46B, 139_ 164.

Stammer, D., 1997: Global characteristics of ocean variability estimated from regional TOPEX/POSEIDON altimeter measurements. J. Phys. Oceanogr., 27, 1743-1769.

Sun, C., and R. Watts, 2001: A circumpolar gravest empirical mode for the Southern Ocean hydrography. J. Geophys. Res., 106, 2833-2855.

Sy, A., U. Schauer, and J. Meincke, 1992: The North Atlantic Current and its associated hydrographic structure above and eastwards of the Mid-Atlantic ridge. Deep-Sea Res., 39, 825-853.

Watts, D. R., X. Qian, and K. L. Tracey, 2001: Mapping abyssal current and pressure fields under the meandering Gulf Stream. J. Atmos. Oceanic Technol., 18, 1052-1067.

Willeford, B. D., 2001: Using stream function coordinates to study the circulation and water masses of the North Pacific. M.S. thesis, Dept. of Physical Oceanography, University of Rhode Island, 193 pp.

Worthington, L. V., 1976: On the North Atlantic Circulation. The Johns Hopkins Oceanographic Studies, Vol. 6, The Johns Hopkins University Press, $110 \mathrm{pp}$.

Zhang, H.-M., and N. G. Hogg, 1992: Circulation and water mass balance in the Brazil Basin. J. Mar. Res., 50, 385-420.

—- M. D. Prater, and T. Rossby, 2001: Isopycnal Lagrangian statistics from the North Atlantic Current RAFOS float observations. J. Geophys. Res., 106, 13 817-13 836. 